\title{
DIGITALCOMMONS
}

@WAYNESTATE-

Wayne State University

Human Biology Open Access Pre-Prints

WSU Press

7-10-2019

\section{Probability, Populations, Phylogenetics and Hominin Speciation}

Niccolo Caldararo

San Francisco State University, cald@sfsu.edu

\section{Recommended Citation}

Caldararo, Niccolo, "Probability, Populations, Phylogenetics and Hominin Speciation" (2019). Human Biology Open Access Pre-Prints. 144.

https://digitalcommons.wayne.edu/humbiol_preprints/144

This Open Access Preprint is brought to you for free and open access by the WSU Press at DigitalCommons@WayneState. It has been accepted for inclusion in Human Biology Open Access Pre-Prints by an authorized administrator of DigitalCommons@WayneState. 


\title{
Probability, Populations, Phylogenetics, and Hominin Speciation
}

Niccolo Caldararo ${ }^{1,2 *}$

${ }^{1}$ Deptartment of Anthropology, San Francisco State University, San Francisco, California, USA.

${ }^{2}$ Deptartment of Biology, City College of San Francisco, San Francisco, California, USA.

*Correspondence to: Niccolo Caldararo, Department of Anthropology, San Francisco State

University, 1600 Holloway Ave., San Francisco, CA 94132 USA. E-mail: cald@ sfsu.edu.

Short Title: Phylogenetics and Hominin Speciation

KEY WORDS: ANCIENT DNA, DENISOVA, NEANDERTALS, POPULATIONS, SPECIATION, HAPLOTYPES, ANAGENESIS.

"Anthropologists were so concerned with the subdivisions within our species and with minor detailed differences between small parts of the species that the physical anthropologists largely forgot that mankind is a species and that the important thing is the evolution of this whole group, not the minor differences between its parts." S.L. Washburn (1963).

\begin{abstract}
A number of recent articles have appeared on the hominin Denisova fossil remains. Many of them focus on attempts to produce DNA sequences from the extracted samples. Often these project mtDNA sequences from the fossil remains of a number of Neandertal fossils and the
\end{abstract}


Denisovans in an attempt to understand the evolution of Mid Pleistocene human ancestors. These papers, introduce a number of problems in the interpretation of speciation in hominins. One concerns the degradation of the ancient DNA and its interpretation as authentic genetic information. Another concerns the idea of "species" versus that of "population" and the use of these ideas in the building of evolutionary diagrams to indicate ancestry and extinction. Since I have dealt with the issue of degradation elsewhere (Caldararo,2016) I will limit this paper to ideas of probability, phylogenetics, species and population. A third issue concerns the theory of haplotypes in the mtDNA. Given the severe constraints on mutations in the mtDNA genome to maintain functionality and the purifying processes to reduce such mutations in the ovaries, putative geographic and historical variations seem contradictory. Local diversity and variations in supposed "macrohaplotypes" are explained as back migrations or back mutations which dilutes the robust nature of the theory. A central issue is what does human variation mean, how much population variation has there been in the past and how does this variation distinguish hominid speciation or simply a process of anagenesis. Some businesses today claim to be able to use DNA analysis to discover past ethnic identities and a new niche in restaurants is producing "DNA" menus. Perhaps some caution is in order. 
As a young undergraduate I was exposed to the lectures and seminars given by Alan Wilson and Vincent Sarich at the University of California, Berkeley. The excitement at the introduction of biomolecular analysis of vertebrate proteins and DNA affected most of the anthropology students I knew. The idea that the analysis of existing patterns of DNA and proteins in living Primates might fill gaps in the fossil record was enthralling. A further implication was that these methods could be used to verify or correct errors in interpretation. This was also a powerful theme at the time. The promise of this work has been largely fulfilled in the almost five decades that have passed (Lowenstein, 1999).

The central debate, I recall, that engaged those who had built their careers on fossil analysis versus the new methods, focused on the assumption that DNA and protein substitutions could be used as clocks to construct phylogenetics. It seemed simply a metaphysical dream that mutations could accumulate at steady rates unaffected by selection or back mutation. Most of those who were skeptical at the time were staunch Darwinists and the idea of neutral theory seemed heresy. My own feeling at the time was that all tools have uses and that methods may be flawed but that they can be perfected. I still hold this opinion concerning molecular genetics, great strides have been made and the effect of debate has sharpened our methods in a number of other areas, as in fossil analysis and morphology.

G.G. Simpson had addressed the issue of evolutionary rates in his 1944 book, Tempo and Mode in Evolution while Brace (1981) wrote a history of efforts in phylogentics. As more studies were applied to the human genome, some questions arose as dates for separation and branching came into conflict with fossil evidence, as with the LCA of chimps and hominins, given dating for $A$. afarensis. When proponents modified their methods to match the fossil evidence some claimed this undermined their methods (Wolpoff, 1989). I analyzed the theories 
and data behind neutral models models with Guthrie in 1998, joining several other scientists who found problems with neutral theory (e.g., Kern \& Hahn, 2018). Moreover, this specifically applies to "pseudogenes" sequences that were assumed to be non-functional (see Li \& Graur, 1991 for example), as in criticism of Haeckel's concept of preserved stages of evolution (Hooton, 1946) but recent demonstration indicates that these sequences are not non-functional but have regulatory roles in expression (An, et al. 2017) was to be expected given the theory of natural selection. The idea that special areas of DNA could escape selection should have been seen as questionable. Certainly conserved areas exist, as in Hox genes, but these are under selection. It also applies to non-coding RNAs (ncRNAs), and is seen in recent work with hyperthermophiles (Klein, et al., 2002). Of course, at first synonymous mutations were thought to be neutral, but it was later found that the usage of synonymous codons was nonrandom. The Genome Hypothesis was an attempt to explain this bias that codon usage is species specific (Li \& Graur, 1991) and this bias seems associated with translational efficiency and accuracy. But even here the variations are not uniform, Sharp, et al. (1988) attempted to show that selection on high levels of expression drove these. They assumed, therefore, the variations were the result of operational constraints, yet some of the high expression examples show more variability than the low use. Either explanation, selection vs efficiency seems to doom neutral theory. Codon usage pattern has been found, especially in parasites to be under significant selection (or codon usage bias) (Mazumder, et al., 2015; Choudhury \& Chakraborty, 2015).

In recent years claims have been made and controversy produced by the application of DNA analysis in the production of evolutionary trees. General comprehensive analyses have been produced regarding molecular phylogenies (Suarez-Diaz and Anaya-Munoz, 2008; Warnow, 2017). But other concerns have been more specific especially regarding how or if 
horizontal gene transfer (HGT) has corrupted our interpretation of the evolution and organization of great groups of living organisms like the archaeal and bacterial phyla (Puigbo, et al., 2009). A number of sequences have been identified as being key to the evolution of the brain without clearly delineating which ones where actually "key" or just involved (e.g., neurospin, see Lu, Peng \& Su, 2007). The search for unique sequences produced claims of the discovery of “intelligence" genes (Jackson, et al., 2002) which were later shown to be interpreted in a more complex fashion (Ghafouri-Fard, et al., 2015). Some sequences were identified that could be used to produce genealogies for contemporary people reaching into the mists of antiquity and beyond, yet based, perhaps on too little data (Sherman, et al., 2018). These problems, regarding how sequences are to be considered to have significance, relates to attempts to create phylogenetic trees of hominin evolution.

In the recent past conflicts over the specific importance of anatomical features found on different fossils created "bushy" trees, especially with Homo erectus/Homo ergaster and the Archaic Homo finds (Tattersall, 1986; 1992), but more so in identifying specific "modern" traits in hominins after 200,000 B.P. (Pearson, 2001). As Tim White (2000) has put it, "Normal variation within closely related extant (modern) species must guide our expectations of variation in species whose members lived in the past. For this reason, osteologists unfamiliar with normal variation in the present are inclined to misinterpret similar variation in the past as indicating multiple species." Some rare cases can emphasize this dilemma, as in androgen insensitivity syndrome (AIS) which produces a range of physiological conditions some producing a typical and functional female habitus. Such an individual can socially function as a female but would be genetically male (XY) due to variations in the androgen receptor microsatellites (Davis-Dao, et al., 2007). Examination of a fossil skeleton of a person who had this condition would lead the 
analyst to type it as female. One of the main struggles is to determine what traits are derived and where there is homology which has so greatly confused ideas of the evolution of the brain in vertebrates, as Striedter (2005) demonstrated. Battles between splitters (those giving species designation to every fossil) and lumpers (those given to proposing variation equals population diversity) have produced a lively intellectual milieu, as in Tattersal's (1992) statement about the , Homo habilis designation which he referred to as a "wastebasket taxon," but also confused the public. It seems the molecular evidence, as it has accumulated supports a more direct scheme, one defined as anagenesis.

\section{The Brain, Intelligence, and Ethnicity}

The big brain became a central focus for paleoanthropologists as it had biologists and anatomists for centuries. Krantz (1961) and Tobias (1971) claimed that the size of the brain in children at the end of the first year of life (approximately 750cc) should be the meridian when a brain size at this point indicates the arrival of symbolic behavior (Holloway, 1996). This is entirely based on the assumption that the human child today creates symbolic language at this time and with this amount of brain. Yet humans do produce speech with smaller brains (e.g. nanocephalic dwarves) and the language of children at 12 months can hardly be said to represent a fully achieved human consciousness. The child gains brain size and neuronal numbers up to about $90 \%$ of adult size by 2 to 3 years of age, (Blinkov and Glezer, 1968; DeSilva and Lesnik, 2008; compare also with Herculano-Houzel, 2016). Yet organizationally and functionally it is quite unlike an adult brain due to incomplete segmental development, as in grey matter in the frontal lobe that undergoes protracted structural development to reach its maximal volume at 11-12 years. The temporal lobe does not achieve its full volume until 16-17 years and most cortical 
regions undergo a cycle of thickening and then thinning reflecting synaptic "pruning" and cell death (Semple, et al., 2013). Still, the capacity of a child can at this age hardly be said to be fully human. By ages 6 to 8 this level of performance usually does arrive, given proper exposure to human society and nutrition. In this regard, Holloway (1996), von Bonin (1963) and Deacon (1997) all placed more emphasis on organization of the brain and connectivity, than simply size.

This problem has surfaced in the debate over the status of the fossils from the island of Flores. The idea that a new small species could be described from the remains led to discussions of potential dwarfism (Lieberman. 2009; Kubo, et al., 2013), pathology and later the process of island dwarfism after the discovery of the more recent fossils of small individuals discovered by Berger on Palau (Berger, 2008; Wilford, 2008; Henneberg, et al., 2014). Thus these cases represent pathology in both the Flores example or insular dwarfism, in the Palau example as they generally fall within the range of certain local groups of Andaman Islanders (Onge). But the effects of mummification and different conditions of preservation should also be considered as in cases like those of the Alaskan and Aleutian mummies (Zimmerman, 1998) in the case of Palau and the Rising Star Cave finds or "Homo naledi" (Berger, et al., 2015, see also Détroit, et al. 2019).

In fact, brain size variation in modern humans is considerable, yet performance as a human is unclear as related to brain size, weight, regions' size, etc. (Holloway, 1980; Dekaban \& Sadowsky, 1978). Holloway (1996) also pointed out the arbitrary nature of the size of the brain associated with species designation, especially regarding Neandertals. As he notes, it is difficult to understand why hominid brains evolved after Homo habilis and I take on this problem in a recent book (Caldararo, 2017). He points out that the slow increase in brain size over the past 2 million years also undermines Dunbar's assertion concerning brain size, social grooming, K- 
selection, monogamy and grooming (Shultz \& Dunbar, 2010). A further critique of the Shultz \& Dunbar (2010) theory is by West (2014) who finds large brain size only associated with social monogamy.

\section{Gene Sequences, Populations, and Species}

Access to DNA sequences for study, especially ancient DNA is limited. The best resource is GENBANK. The Cambridge DNA Concordance appears to be no longer available. Other databases with population comparison capability like the International Genome Sample Resource (IGSR) lacks comprehensive data and similar sites have been strapped to expand due to costs and lack of funding. The final 1000 IGSR data set contains some 2,500 present-day individuals from 26 populations with a low coverage of 2-6x whole-genome sequencing (WGS) data, mainly exome sequence data available for all individuals and only high coverage for 24 (Sims, et al., 2014; Sudmant, et al., 2015). Sherman, et al., (2018) have summarized the various aspect of current databases and the strategies that produced them. Low-coverage Whole Genome Sequencing (WGS) is a sampling strategy that overcomes some of the deficiencies seen in fixed content SNP array studies. Linkage-disequilibrium (LD) aware variant callers, such as the program Thunder, may provide a calling rate and accuracy that makes a low-coverage sequencing strategy viable. This is due to the costs of sequencing whole genomes. Tests of accuracy, as by Bizon, et al., (2014) indicate acceptable results.

However, making assumptions from this small sample of contemporary humans given a population of over 6 billion may skew the actual penetration and retention of Neandertal genes and other archaic populations (e.g., Denisovans). Sankararaman, et al., (2014) used this data base to make a number of propositions concerning modern human ancestry, derived also from 
assumptions regarding both Neandertal demography and the evolution of population expansions and selection over the past 30,000 years Their methodology of inferring Neandertal haplotypes due to the impossibility of reconstructing the short ancient Neandertal DNA fragments is interesting but cannot be relied on to be more than suggestive. Other assumptions are equally curious. Most notable is the proposal that reduced genes in Neandertal ancestry that are highly expressed in testes than other tissue, or a discovered 5 fold reduction of Neandertal ancestry X chromosome genes, are both the result of selection against them. Projecting such conclusions over 30,000 years from partial knowledge of the Neandertal populations and from a lack of complete sequences and a small contemporary sample seems premature at best. More comprehensive sampling, deeper coverage and more precise methods of producing ancient DNA sequences from preserved samples will probably change this picture.

Nevertheless, thinking of how much our current Neandertal or Denisovan samples represent the populations from which they come and how these samples are used reminds one of the typological thinking that dominated taxonomic research until Mayr $(1963 ; 1970)$ put the emphasis on population variation. Typological classification tended to confuse breeding populations with variation within populations. Relethford (1994) has attempted to estimate ancient population diversity though not entirely convincing. On the same note, identifying trends in selection from variation was difficult and determining divergent selection has produced significant interest in recent years (Whitlock and Guillaume, 2000). This is demonstrated in a recent book (Stringer, 2012) where the author refers to the differences between Homo sapiens and Neandertals in the size and shape of the vestibular canals of the ear. The information he was drawing on was small and limited and when more human samples were examined there was even a greater similarity between Homo sapiens' size and form and bonobos (El Khoury, et al., 2014). 
This would indicate that this trait does not provide a firm comparative basis for hominid evolution.

To some extent much of this thinking attempts to show direct relationships between adaptation and changes in genes and rather borders on Lamarkianism. This is particularly strong in efforts to explain the evolution of the "big brain" in hominins and the appearance of language. Deacon (1997) refers to the work of James Mark Baldwin (1902) whose work was limited to human psychology but argued that "biases" coupled with learning and behavioral flexibility could modify inheritance of future kin. Little in Baldwin's work differs from the theory of inheritance of Lamark (1830) but Lamark's work was bolstered in a wide knowledge of the animal and plant world, embryology and development. He created a coherent theory of evolution and laid the framework for today's transgenerational epigenetics (Cameron, 2017; Haig, 2007; Weaver, et al., 2004). Though flawed, and given the knowledge and instrumentation of his day, Lamark certainly provides a more coherent view of epigenetics than Baldwin. In fact, few can even discuss or explain the "Baldwin effect" without reference to Lamark (Burman, 2013). Even Waddington's (1942) “genetic assimilation” which he tried to distinguish from the "Baldwin effect” was called "Lamarkian" by Simpson (1944), though Waddington (1956) had the benefit of extensive experimentation with cells and the problem of agents of development and genetics. Where Baldwin's idea appears metaphysical in its connections, Waddington's is based in his experience in embryology and cytochemistry. One might argue that Baldwin's concept is an elaboration of Darwin's (1989/1838) conjecture on Baboon “metaphysics” drawn out recently in Cheney and Seyfarth's (2007) and the evolution of the "mind." But the adaptive "arms race" in nature, as between Bordetella bacteria and bacteriophage (Heyman, 2005) is a process of communication. The bacteria is able to change its outside cell surface almost at any 
time, yet phage has evolved diversity-generating retroelements (DGRs) that achieve "targeted" genomic adaptation. Such successful response is a process of "information processing" by the phage, no matter at all if we call it Baldwinian or Lamarkian. This also relates to the "extended phenotype" concept and examples given by Dawkins (1999).

\section{Graph Theory, Nodes, and Neighbor Joining for Discovering Paleospecies}

How charts are composed using traits depends on concepts of affinity and difference. As John von Neumann (1951) noted, this starts with a conception of the complexity of organisms and how they can be subdivided into parts, seen as elementary units. This stands for the actual biological process that has arrived at the complexity we address. Such abstraction allows us to apply logic or math to the complexity. Though that complexity has built up over time and represents systems that are difficult to isolate in any organism or populations of organisms over time (Margulis, 1981). Complexity leads to the consideration of similarities and differences between individual specimens. This involves weighing and quantifying differences among individuals in populations and fossils. These similarities and differences can then be placed into categories of primitive and derived traits in relative emphasis. From this process are erected cladistics, stepping stones isolated from reality yet pose as representations of transitions as Le Gros Clark $(1934 ; 1955)$ carefully described. This is especially true with regard to the distribution of traits in populations and the assignment of specific associations as derived. Yet this depends on a comprehensive knowledge of the sample of the populations studied. A lack of which can result in distortions. An example of this is the generally shorter tibia of Neandertals (Lovejoy \& Trinkaus, 1980), a population whose tibiae most paleoanthropologists thought to be shorter than contemporary human populations. However, at least one contemporary population, 
the Maori, have tibia in the same range (Davidson, 1984; Houghton, 1980; Schofield, 1959).

This brings us to the question of how malleable traits are and how to assess form based on use, as in the example of the feet illustrated here from the Huaorani of Ecuador, Figure 1 (from Kane, 1995, see also Earnest and Wang, 2012). Another example is the debate over the variations in the supraorbital torus (Russell, 1985). Many traits in modern humans seem to be the result of the very recent self-domestication of sedentary life, as in hair (Caldararo, 2005). There is recognized a genetic architecture to domestication (Wright, 2015) which appears to apply to recent humans (Wilson, 1988). At the base of this process of cladistics is the principle of parsimony (the fewest steps to a conclusion) which is utilized in the reconstruction of ancestral character states (Pagel, 1999) or that of maximum likelihood (using "local" or "global methods") based on models of how evolution proceeds, or in the form of maximum parsimony trees, the minimum evolution (Fitch, 1971; 1977).

Math has been a major tool in the interpretion of the relationships of traits and the categories formed from observed differences. Bootstrapping and graph theory are also popular confidence methods used in phylogenetics. The use of graph theory in phylogenetics has a long history. The idea stems from the use of a field of points carrying certain values that are joined together as pair wise relations into nodes, these may be connected by arcs, edges or most often by lines. The means of associating specific fossils to unique points depends on the interpretation of the qualities of the fossils to some scientifically established model of a species. The creation of "rooted" and "unrooted" trees, (see Figure 2) is the usual outcome. In the former case this produces a most recent common ancestor (MRCA) and depends on the determination of genetic distance. In either case, both designs are based on ideas of divergence rates, including the molecular clock theory (Battistuzzi, Filipski and Kumar, 2011). Some of these methods, 
including those utilized by Cavalli-Sforza and Edwards, Wright's Fst, Latter and Reynolds and Nei's produce inconsistent results (Libiger, et al., 2009). These methods also lack reference to complex genomic events such as the role of transposable elements (TE) in speciation and the production of "hot" and "cold" genomes (Ricci, et al., 2018). Studies of proteins that interact with viruses indicate relationships between viral infection, introgression and viral selection in Neandertals and modern humans (Enard \& Petrov, 2018). Knowledge of pathogen selection seems essential to understand human evolution (Caldararo, 1996).

Bootstrapping was a product of Bradley Efron's efforts to estimate variances in a population from simple or limited data. It involves the statistical mechanics of "resampling" from the available data to project logical aspects of the true population and missing data (Efron, 1979). Often these methods are referred to as "smoothing techniques" as in Kernel Density or the Probability Density Function. Methods such as Bootstrapping and graph theory provide a measure of relative likelihood of a random value within any given sample. As with Fisher's Exact Test where a sample is small, one can obtain a confidence in probability variation, though as in all these methods, certain assumptions are essential. In the case of Fisher's Exact Test it operates under the null hypothesis that there are no differences in the population proportions. Since all populations vary over time this produces estimates of the tail of sampling distribution (Blalock, 1960). Inevitably, these methods attempt to extend the data by using statistical models generating fitted values that pass known data points to predict unknown values about populations. It should be kept in mind that there are discrepancies in applying such models to real populations, comparing models and real data often show models tend to over estimate populations and segments (Conn, et al., 2015). 
How closely any specific fossil can be so associated depends on how measurements are made and fossils described given in the model. The first problem is in the types of errors that can be made and relates to Error Theory (Scuro, et al., 2004). Efforts by Hess (1945) and Brothwell (1961) to increase confidence in measurements of variants led to considerations of multiple measurements (Rao, 1948; Laughlin and Jørgensen, 1956; Brothwell, 1959 and Penrose' 1954 "size and shape statistic"). Penrose's approach has been found more useful in some cases than M-statistic methods (Groeneveld and Kieser, 1987). However, for large data sets M-statistic methods have produced more useful results, especially in genetic and medical meta-studies (Magosi, et al., 2017). Still, some researchers, especially in cranial studies, favored concentration on a "single measure of divergence" such as that developed by Smith (1911) for convenience and modified by Grewal (1962). The validity of this approach has been discussed by Berry (1964) Berry, Evans and Sennitt (1967), Howe and Parsons (1967) and Berry, Berry and Ucko, (1967). This involved averaging measures of divergence and applying principal component analysis (PCA) to the data as shown by Howells (1973), and it is sensitive to the relative scaling of the original variables. PCA was developed by Pearson (1901) as a means of finding “...lines and planes of closest fit to systems of points in space," basically making approximations between points of measurement (Wold, Esbenson and Geladi, 1987).

PCA attempts to deal with the distribution of variables and transforms them into a set of values often using additional computations to adjust the set of values. An example is seen in eigenfunction decomposition where the "noise" of the measurement system has undue influence and it could hamper solutions (detection). A similar problem arises in molecular phylogenetics where gaps in sequences are present, length varies, substitutions are present and determination of similarity in sequences rests on assumptions of affinity, both in protein sequences and DNA. 
Efforts to address this problem began with Jukes and Cantor (1969), then with an algorithm devised by Needlemand and Wunch (1970) and finally with Sellers (1974) for amino acid differences. Such efforts to "smooth" the noise of variation is why we have focused attention on this problem in several publications on DNA differences (Caldararo \& Gabow, 2000; Caldararo \& Guthrie, 1998; Caldararo \& Guthrie, 2012; Caldararo, 2016). There have been earlier debates over the subjectivity of these methods (Felsenstein, et al. 1982; Thorne, et al., 1991).

To attempt to "smooth" the noise of variation with paleospecies requires a means of describing the population of the fossil model and its hypothetical variation over time, including gender variation, age characteristics, population size over time and potential hybridization events. In this way the existence of Australopithecus afarensis can be described as existing for some million years and probably produced over that time some 3 or 4 million individuals considering a low crude birth rate (CBR), survival given predation and disease beginning with some 100 fertile individuals. Boas (1979) makes some assertions concerning early hominid population density. We assume stability in morphology to come to this conclusion given our sample over this million-year period. The question is do these fossil samples represent the real population diversity of the species we call Australopithcus afarensis? Recent analysis of dental evidence from the Woranso-Mille specimens has suggested that Australopithecus afarensis and Australopithecus anamensis could even be considered one species (Haile-Selassie, 2010). The suggestion of anagenesis at this time in the fossil record has been made before (Kimbel, et al., 2006). Howell (1996) was dissatisfied with the various species concepts and came to concur with Trinkaus (1990) in regarding hominid fossils as paleo-demes (p-demes) or portions of dynamic evolutionary units that could not be confidently assigned to an understanding of the particular population at any time. However, a confirmed 'splitter' as Tattersall, he urged the consideration 
of multiple species among the many fossil specimens available at the time. Yet he came to consider anagenesis as a form of orthogenesis or progressivism.

The same problem was addressed by Rightmire (1990) for Homo erectus and Tobias (1971) and Wood (1991) for Homo habilis. Zachos (2016) has produced an excellent historical summary of the species issue. Still one has to wonder why science recognizes one species of hominid, Australopithecus afarensis existing for more than a million years and then also Homo erectus for a million years but then a rapid production of species after 500,000 B.P.? While rate of speciation and size are correlated among fish with the exception of African cichlids (Rabosky, et al., 2013), fast speciation rate is related to chromosomal evolution and population structured into small demes (Bush, et al., 1977) which would parallel Howells' suggestion. Howell's idea, as I recall, came about in reference to Alan Wilson's work, but the increased speciation has some support in the Pleistocene from the work of Avise, et. al. (1998). Their information appears to support Tattersall's perspective (1992). Yet Lordkipanidze, et al. (2013) argue against the above presented idea (see also, Spoor, 2013) and new finds of what appears to be Homo floresiensis may be 800,000 years old and indicate island dwarfing (van den Bergh, et al., 2016). Alternatively, Dembo, et al., 2015) using a very large craniodental sample (supermatrix) under Bayesian analysis (a method of statistical inference of probability for treatment of a body of information given missing portions) addresses the issue via stepping stone sampling. They argue that their analysis produces the best fit for these data based on fossil evidence and they regard the position of Australopithecus sediba as a transitional fossil between late Australopithecines and early Homo. They agree with Berger, who, opposes the idea that Australopithecus sediba is a late Australopithecine without issue. Brace (1981) focused on dental information, and his conclusions fit with my consideration from a philosophical point of view, that it would be very 
difficult to distinguish between the population of the "last" australopithecines and the "first" Homo. Brace (1981) was critical of such leaps of classification. The transition should be "messy" with a variety of interfertile but varied types; we are not dealing with Cuvier's divinely created species, but rather a dynamic process of selection and survival over time. Despite advances in phylogenetic analysis and comparative data (e.g., Freckleton, Harvey \& Pagel, 2002; von Cramon-Taubadel, 2014) problems of type I errors are common and assumptions of statistical comparative methods must be constantly checked (Diaz-Uriarte and Garland, 1996).

Data produced by a variety of individual scientists measuring and interpreting fossil remains and reconstruction produce the same problem Howells $(1973,1989)$ faced in addressing speciation and variability in human crania. Recent reference to neutral theory has "smoothed" some of these differences (von Cramon-Taubadel, 2014) but neutral theory is also a central problem (Kern \& Hahn, 2018). Disgreement resulted in Howells attempt to eliminate operator error by making his own new computations and comparing them with existing ones. Relethford (1994, 2004) and Roseman, (2004) argued from their own computations, for an association cranial architecture and genetic constraints specifically limited environmental variability in samples studied. Later studies contradicted this finding, Williams, Belcher, and Armelagos (2005) argued, "the possibility that skeletal material could be accurately sorted by geographic origin, at any other level than geographic extremes, is quite small." They based this argument on the misclassification of a high percentage of ancient skulls into modern reference samples. Hubbe and Neves (2007) criticized the software Williams, et al. (2005) used in their analysis and agreed with Relethford (2004) and Roseman (2004). Similar problems have attended attempts to study quantitative traits assuming variance patterns are proportional to additive genetic variances and that phenotypic variances can be used to estimate underlying genetic variances. However, 
this could often only be achieved by molding the data to fit the theory (Cheverud, 1988), or modifying the methods ("jackknife" to the bootstrap), but could also produce bias in the results (Reale and Roff, 2001). At the same time a number of researchers have argued that global patterns in human cranial variation are "primarily" shaped by neutral evolutionary forces (von Cramon-Taubadel, 2014). Explaining this "balance" of forces, however, becomes quite forced and at times the ideas of "neutral" and "evolutionary" seem juxtaposed to deny selection pressures. One wonders if the attribution of "force" and cause to neutrality has not become a default explanation as was the case in early archaeology when objects or buildings were called "religious" when no other function could be discovered. The more we know about molecular genetics the more it seems neutral theory will go the way of introns as "junk DNA" (Wang, et al., 2013) or the so-called pseudokinases that are highly conserved yet thought to be inactive (Sreelatha, et. al. 2018). What is lacking is our knowledge of function in these cases.

The same problem attends producing phylogenetic charts from DNA or ancient DNA (aDNA). Establishing nodes based on agreement of samples is complicated by the number of different transcripts produced during amplification and resulting from either degradation or contamination (Caldararo \& Guthrie, 2012). This also applies to creating nodes and branching established in sequence variations between samples that are separated in time by thousands, if not tens of thousands of years. An example would be comparing Neandertal, modern humans or chimpanzees samples (Caldararo \& Gabow, 2000). How much variability can the computing process "smooth" and still have an authentic relationship that accounts for population diversity and microevolution?

Similarly in Howells' work, the problem of the production of phylogenetic trees based on neighbor joining requires equating measurements that have been collected by different scientists. 
Physical measurements are one problem, but in DNA, one has to determine what genes, and what sequences are significant. This process requires inputting these genes and sequences as data points and using an algorithm to manipulate them to discover relationships between individuals in groups that are considered (Saitou \& Nei, 1987; Haws, et al., 2011). The main problem is how many variations create groups? With DNA, especially comparing ancient DNA to modern, one has to ask how distinct and authentic are the aDNA sequences, especially when fragments are realigned (Caldararo \& Guthrie, 2012)? This was our initial question with the first Neandertal and Denisovan published sequences and interpretation; how could these people be so different from all people before or after? Our analysis of the published sequence showed that the authors' idea of uniqueness was a misread of the data. This same problem seems to be true of the analysis of sequences from three ancient individuals from Vanuatu. The authors of this study (Skoglund, et al., 2016) make a similar claim, "The distinctiveness of the ancient individuals is also highlighted by their high differentiation from all present-day groups $(0.05<\mathrm{Fst}<0.26$; between all modern individuals and the ancient Vanuatu individuals, using the statistic Fst, which is proportional to average squared allele frequency difference)." As in the first Neandertal and Denisovan cases, we are curious as to what a detailed, independent analysis of the ancient sequences will provide. Already questions of authenticity of the material and methods have surfaced (Lewis-Kraus, 2019).

While methods have produced errors at times, the recent example of the East African skeleton that produced 4,500 year-old aDNA with some surprising conclusions was quickly corrected (Callaway, 2016). This is an indication of how well researchers are working together and improving techniques. The use of DNA barcodes and thin-film biosensor chips have improved species identification in living species, but limitations remain (Pecnikar \& Buzan, 
2014). Some attempts to produce strong phylogenetic signals use concatenation, or the assembly of hundreds of genes into a single data set (derived from string theory in computer science). However, this method often produces trees that do not agree with each other and the operators have to suggest a "best fit" based on somewhat subjective assessments (Kubatko \& Degnan, 2007; Salichos \& Rochas, 2013), not unlike bootstrapping discussed above. In fact, when estimates from concatenated data under coalescence are used it can provide strong support for incorrect phylogeny (Kubatko \& Degnan, 2007).

As Caldararo argued in a recent paper (Caldararo, 2016), definitions of what is a species are necessary to understand differences in DNA sequences in descendent populations. How many differences make a species? We can demonstrate many differences in contemporary populations, including different ear shape, hair color, hair type, cranial shape, skin color, blood types, etc. Yet no one today would propose that such differences are indicative individuals possessing such differences or combination of differences as different species. Some differences are quite marked as in the Lacrimal-ethmoid sutures or in the possession of cervical vertebrae (Schultz, 1950; Grey, 1977). Schultz (1950) also stressed developmental variation the way individual aging could produce dramatic differences similar to juvenile humans showing several sternabrae, but these fuse in adulthood. As Gould (1996) argued, we tend to be driven by extremes or by means and miss the nature of population diversity in either case. Gould's idea applies to other ideas about the brain, in particular recent claims on the evolution of brain shape in Homo as in the work of Neubauer, et al., (2018) where an idealized uniformity is produced by eliminating outliers from a selected population. However, when larger samples are utilized other researchers find significant variation in brain shape by variation in size and sex (Reardon, et al., 2018). We base our general determination on the reliable process of fertility and the production 
of fertile young, known as the Biological Species Concept (Mayr, 1982). However, we cannot apply this rule to fossil species because some "species" scientists have acknowledged in the past can produce viable young in matings, as in Papio anubis and Papio hamadryas (Bergman \& Beehner, 2004; Lewin, 1989).

It is interesting that the time line of discoveries of major fossil entities has taken place in almost reverse order to their age (Table 1). Sahelanthropus tchadensis is the most ancient at about 7 million years, and the most recently discovered. However, some recent finds that have been given species designation, may not be new species, as in Homo naledi, as I note in this paper. Yet one must also recall that the Piltdown Hoax took place in 1912 between numbers 2 and 3 in the figure above and distorted our understanding of hominin evolution for about half a century. Fashionable ideas and precedent have had their effects, as Weidenreich (1946) notes, first people tried to divide humanity by skin color, then by constitution and vapors, then head shape and ideas of civilization, all of which were not supported by science (Firmin, 1885/2002). Today we face a similar problem with the use of DNA.

There are at least a dozen concepts concerning designating animal groups as different species, including the Phylogenetic Species Concept (PSC), the Species Recognition Concept (SRC) and the Ecological Species Concept (EPC). Each has problems and refining definitions requires agreement. Obviously, the SRC, like the BSC would be impossible to apply to fossil paleospecies. With the PSC of Eldredge and Caracraft (1980), the focus is on morphology as a means to determine a diagnostic cluster of traits from individuals from which discernment of a parental pattern is possible. However, the question is what is the necessary number of traits and individuals required to establish the diagnosis? Numerous methods have been used as Rightmire's (1990) detailed measurements and computation generating diagrams to value trends 
in trait appearance. However, it is not clear how reliable these methods are in terms of meeting expectations. Meirmans (2012) points out a similar problem of expectations with genetic distance analysis that concerns factors like Isolation by Distance (IBD) and the use of programs such as Mantel test, or data checks using AMOVA. He also tests SAM (Spatial Analysis Software for detecting candidate loci for selection) and FDIST (as a measure of differentiation or diversity). He found both identified an excess of loci with $\mathrm{p} \leq 0.05$ due to program assumptions. Attempts to create categories is also confounded where taxonomists have found groups of organisms that are morphologically indistinguishable from each other but belong to different evolutionary lineages based on genetic analysis (often called, “cryptic species” see Saez, and Lozano, 2005). We are not concerned here with back mutations, reversals (Domes, et al., 2007) or pseudo-atavism (e.g., Hypertrichosis) features appearing in embryology, as Schultz (1925) noted, or pathological conditions that mimic these ideas as in Uner Tan Syndrome where affected individuals must walk in quadrupedal posture (Humphrey, Skoyles and Keynes, 2005; Uner Tan, 2009).

Similarly, Roisin and Korb, (2011) suggest that differences in coding of characters has been represented as being the source of conflicting phylogenetic conclusions in termites. As Maynard Keynes (1921) once cautioned, one should not mistake probability for reality. How much gene flow and population variation undermine the veracity of analysis for species determination and how can scientists reliably apply similar forms of analysis to paleospecies? An approach to the problem was published by O’Hara $(1993 ; 1994)$ who focuses attention on the nature of the generalizations that lead to representations of phylogenetic relationships. Similar caution was expressed by Sean Eddy (one of the authors of the book, Biological Sequence Analysis) (Durbin \& Eddy, 2013), who was dismayed by the way people added to "sequence 
weighing" in an ad hoc fashion to the point that he considered there was so little statistical basis for many models. He called their work, "sequence weighting crap" (Heyman, 2003). Lior Pachter, author of the program SLAM criticized the claims of program creators who compare programs and argue theirs is always better. As he implies, not everyone can be right. He adds a more detailed discussion on biostatistical issues related in this paper in his blog: https://liorpachter.wordpress.com/2015/06/09/i-was-wrong/. On a more troubling note, Shen, Hittinger and Rokas (2017) argue that contentious relationships in phylogenomic studies can be the result of small subsets of genes affecting large data matrices on specific nodes of data. Often elimination of single gene inclusion can diminish support for branching. This expands on earlier work by Rokas, Williams and Carroll (2003). For hominins scientists have attempted to use physiological differences in the surviving fossil material to construct logical species groupings with similar conflicting conclusions.

There have been successes and advances in genetic techniques and applications, and certainly advances in gene therapy (for example in Car-T research and treatment). These indicate greater precision in identifying sequences and interpreting variations for biological ends. However, as with all research, there have also been terrible setbacks (for example, see review in Crow, 2017). Statistician Genevera Allen criticized machine learning applied to medical applications at the 2019 American Association for Science meeting. She argued that the programs were designed to produce solutions to every problem when a physician, faced with symptoms of an individual patient might decline treatment. Similarly there has been a long history of disagreement over what significance to place on differences, including morphology and, now in sequence variation. A drawing appears in Howells' 1959 book showing two different scenarios. It contrasts the idea of a straight line evolution of hominines or anagenesis, with a 
bushy "hat rack" model. Howells borrowed the direct version of the diagram from a diagram Weidenreich (1947) had developed from an earlier one by Gustav Schwalbe (Brace, 1981). The above researchers, like Dobzhansky (1944), saw the evidence of hominin evolution to support a wide-spread, polytypic species. Brace's (1981) adaptation emphasizes the idea of transitions and the lack of population information as well as the problem of determining speciation. But he mostly condemns the effects of cladistics in confusing variation with speciation. An extreme example of this was Schwartz's (1984) use of cladistics to demonstrate that the orangutan (Pongo) shares the greatest number of derived features with Homo and thus according to cladistics should be considered the closest relative of humans! How do researchers determine the differences or similarities that are possible to group or separate fossil evidence into such charts? While theoretical arguments (including drift and forms of selection) can develop models of speciation (Whitlock and Guillaume, 2009), the existence of widespread interfertile but highly polytypic species (e.g., wolves and coyotes) provide an alternative model more applicable to hominin evolution.

Recent trends can overwhelm consideration of earlier trends' and change the focus to recent traits as characteristic of our species. An example of this was published in Evolutionary Anthropology in 2004 (Neufeld \& Conroy, 2004) where a type of human hair was considered to be unique to all mammals. On examination, however, it was demonstrated (Caldararo, 2005) that the authors had overlooked the fact that humans display several types of hair and that the type focused on by the authors (Neufeld, Conroy, 2004) was likely a product of selection due to domestication (Kruska, 2007) or self-domestication (Caldararo, 2017). Recent traits in humans may also be such products, not only of domestication, as seen in other animals, but also of selective pressures resulting from recent patterns of adaptation to sedentary life (e.g. disease). 
Additionally, recent traits may also be representative of the lifestyle of tropically adapted Anatomically Modern Humans, whose trends extend from the Upper Paleolithic.

Researchers have heralded certain groups of DNA, called haplotypes as designations of ethnicity, ancestry, race and used them to tell stories about the evolution of populations (KimchiSarfaty, et al., 2007). Trees have been constructed detailing evolutionary changes, associations with locations and historic events, including migrations. Templeton (2006) defines a haplotype as, "A haplotype is a multisite haploid genotype at two or more polymorphic sites on the same chromosome in a defined DNA region." He argues that, "Haplotype trees can be used to reconstruct past human gene-flow patterns and historical events, but any single tree captures only a small portion of evolutionary history, and is subject to error." Therefore, as with discussions of species, a caution on the discussion of haplotypes is in order. Claims that certain sequences have evolutionary significance require careful consideration.

Haplotype (gene) trees and not the same as species trees. Yet our current models of haplotype evolution use the human genome reference (GRCh38) which was constructed from several individuals and derived from large-insert BAC clones, thus the sequence from a single clone insert often represents "human reference" by chance. Thus Audano, et al. (2019) state that “... any single human haplotype may be missing or contain sequence variants that are not present in the majority of humans." We also discuss the results of Sherman, et al (2018) on this as well below.

In the 1990s studies of the genomes of various organisms produced general ideas of horizontal gene transfer (HGT) from Archaea and Bacteria to vertebrates without any evolutionary intermediates. Subsequent research appeared to show these findings were in error (Stanhope, et a., 2001). Later research, clarified some evidence of (HGT) but the issue remains 
clouded (Puigbo, et al., 2009). HGT is usually distinguished from gene flow among populations of the same multicellular species, where the term now is "introgression." Crisp, et al. (2015), demonstrates that there appears to be more support for the idea of HGT in vertebrates and humans. This example shows how tenuous are our findings and the problems that interpretation can bring. HGT reeked havoc with ideas of species and trees. But new information and technology will cause us to reexamine our assumptions; the same should be the case with haplotype analysis.

Haplotypes, despite a lack of evidence or understanding of a selective advantage, are often credited with substantial significance in evolution, as in the case of FAM72 and SRGAP2 (Charrier, et al., 2012; Dennis, et al., 2012). FAM72 has been identified as a neuronal progenitor cell self-renewal protein with tumourigenic effects (Kutzner, et al., 2015). Haplotypes are not eternal and arguments that they are associated with nations, peoples, or specific geographic areas are at best wrong-headed (Hay, 2015). This is most evident in the way haplotypes have been associated with ethnic groups and localities. For example, in the discussion of the frequency of the Taq I y-globin polymorphism put forth by Wainscoat, et al. (1989), they argue that the polymorphism is found in $0.47 \%$ of the Nigerian population and at $0.36 \%$ of the South African Black population, and that is not found outside of Africa. They conclude that this indicates a major division of human population. The fact that sample sizes were small (132 to 11 individuals) and that they do not state what Nigerians this included or what South African "Blacks" lends a rather small indication for a "major" division. What about those Nigerians, the majority who did not have the haplotype? Alternatively, regarding the South African "Blacks," can $0.47 \%$ and $0.36 \%$ represent all Africans? It is obvious that selective pressures change and affect distribution of such traits as in the variation between highland and lowland populations in 
y-globin gene promoter polymorphisms (Rottgardt, et al, 2010). Highlighting these questions is a recent study by Sherman, et al. (2018) which includes a deeply sequenced dataset of 910 individuals of African descent that revealed 125,715 unique contigs (contiguous sequences). As Sherman, et al., (2018) note, "Among other problems, the addition of alternate loci as separate contigs can mislead sequence alignment programs, which were designed under the assumptions that each read has a single true point of origin and that the genome is represented as a linear haploid sequence."

There is a major contradiction in ideas of the evolution and permanence of haplotypes. In mtDNA, mutations disrupt the efficient functions of the very limited body of space available and they create a high genetic load which could “... imperil survival of the species.” (Wallace, 2015). Wallace (2015) argues that this is controlled by a process in the ovaries where the proto-oocytes and oocytes with the most severe mutations are selectively eliminated. This raises the question, if there is so close a selection and lack of room for functional variation, how did the macrohaplotypes evolve and do people in these groups differ in the functional efficiency of the mitochondria? Caldararo and Guthrie (1998) discussed this problem and the evolutionary context required for adaptation in mitochondria products. This certainly undermines the idea that mtDNA neutrality provides for both an evolutionary clock and that diversity in mtDNA indicates ancient roots (Stoneking and Cann, 1989).

Wallace (2015) asserts that tightly coupled mitochondria function more efficiently in warm climates and lightly coupled ones in colder ones. Wallace's research assumes the degree of climate and does not provide definitions of the various climates. However, significant variations occur within local populations as in Finland, and found also in runners in Kenya. Variants thought to increase functionality at high altitude are found in only Tibetans with 
macrogroup $\mathrm{M}$ and not $\mathrm{N}$ haplogroups where it is theorized to produce non-functionality. Yet these people (with $\mathrm{N}$ ) function nonetheless and the lack of local uniformity and geographic limitations would seem to cause some concern if we are dealing with an adaptive and evolutionary condition. The clinical deficit or benefit seems to be absent. As is shown from the regional radiation of human mtDNAs published in the MITOMAP (2015) one would expect distinct separations, yet when viewed as actual data, we find considerable diversity geographically with little hard separation (Rishishwar \& Jordon, 2017). Wallace's theory explains exceptions in the geographic areas of the macrohaplotypes as back migrations or back mutations (Wallace, 2015). However, he bases his conclusions on a very small set of samples, especially in Africa. There has also been a history of the production of "novel" variants due to a failure of investigators to reference appropriate databases (Bandelt, et al., 2009). In fact, assignment of variants to haplogroups depends on correspondence between the control region and "informative" SNPs from the coding region as well as " ...the availability and quality of phylogenetic information.” (van Oven and Kayser, 2009). This relationship can be seen to represent a certain degree of circularity.

Haplotype pattern of inheritance differs from that of genes common to descendent groups or species from a common ancestor (as in Hox genes, see, Carroll, 1995), as illustrated in Figure 4. Haplotypes change over time, as does their frequency among local groups due to genetic drift, selection and mutation; new ones appearing and old ones disappearing. Thus, statements that specific haplotypes can be used to identify ancient migration patterns or "homelands" are ill advised and most likely entirely false. Ideas of such essentialism of haplotypes in specific people or peoples creates the same problems as did ideas that certain cranial types were associated with specific peoples in the $19^{\text {th }}$ century, and represented certain behavioral qualities or abilities, 
much to the disgrace of the anatomists who championed those theories (Firmin, 1885/2002). A variety of biases have been criticized in genetic studies (Gould, 1996a), and because of these debates, new interpretations and methods have produced more robust and scientific results (Gokcumen, 2018).

Individuals in populations and some populations have gained or lost sequences, but the history of gene flow, transmission, and loss remains poorly understood. Relethford (2001), reviewing Alan Fix's (1999) book on the use of molecular biology to study human migrations, puts this elegantly describing the danger in trying to abstract a single pattern of human migration. This danger is particularly evident when the goal is to make inferences about ancient human populations. Fix concludes “...Perhaps the real take-home message from these comparisons is that there is not one 'real' human population that typified human populations throughout the long span of our evolution."

In some cases the DNA sequences (e.g., DUF1220, see Dumas, et al. (2012) identified as causative agents, (as with megacephaly and autism), are so variable and diffuse in association with clinical expression as disease, that causation seems doubtful at best (Brunetti-Pierri, et al., 2008; but also, Perry, et al., 2008). The assumptions surrounding "association," "correlation", and statistical validity have been often found subsequently, if not false, distorting (Nuzzo, 2014). Scientists once thought autism was a developmental disturbance that disappeared at adolescence. Scientists now know this is not true. The condition seems to be the result of a number of genetic factors with a complex interplay of linkage across chromosomal regions (Schumacher, et al., 2007). In the case of dyslexia, it is interesting that it varies by language, as in Chinese children vs English children. This variation indicates that dyslexia is not the same in every culture or has a universal biological cause (Siok, Perfetti, Jin and Tan, 2004). The same research suggests that 
dyslexia in Japanese is intermediate between Chinese and a language like English (Pilcher, 2004). What is most interesting is the fact that the English-speaking children and Chinesespeaking children develop dyslexia pathologies of the brain in different areas. The effects of culture on brain development would seem possible, given our long history of studies on brain development and effects of experience (Diamond, 1988). Epigenetic studies in promoter and enhancer activity is clearly an area of future work in human corticogenesis (Reilly, et al., 2015) and may define a number of exogenous factors.

The Vernot, et al., (2016) chart does not clearly indicate the idea of genetic exchange by living co-mingling populations of the same species. Instead it is easily read as indicating separate species and an undefined transmission of genes, perhaps by hybrids. It is known that creating phylogenetic trees from multiple sources, as in hybrids, explicit trees are produced as opposed to implicit trees, and can represent different networks that result in the same tree (see Pardi \& Scornavacca, 2015). A chart by Mendez, et al. (2014), their Figure S4 (reproduced here as Figure 6), suffers a similar distortion as the chart produced by Vernot, et al. (2016) and both give the impression of speciation between Melanesians, Eurasians and African populations. A more representative means of illustrating the transmission of the haplotype at STAT2 between these groups appears as Figure 7, where I have modified their chart to indicate interfertile populations of the same species. In addition, this chart clarifies the time frame of the past 200,000 years and indicates, by the arrows, continued gene flow between populations of hominins. This is a form of anagenesis, or the idea that the human species of Homo sapiens probably should include Neandertals, Denisovans and other mid Pleistocene hominids if we assume interfertility which is the basis for the Biological Species Concept. This view seems all the more reasonable because in recent years the extreme views of Neandertals, both in terms of 
physiological differences of the Archaic Homo group in general (Pearson, 2001), as well as the behavioral differences assumed in the past have been undermined (D'Errico, 2003). However, ideas of evidence of behavioral modernity differ significantly and recent finds of paintings and drawings in Borneo contradict unilineal models of its spread (Aubert, et al, 2018).

The Mendez, et al., (2014), chart appears only in the supplemental materials. Moreover, the new find at Jebel Irhoud (Hublin, et al., 2017) supports my view of a more inclusive transition of Archaic Homo to modern human. By using discriminate analysis, Pearson (2001) produces a figure with unweighted pair-methodology using arithmetic averages (UPGMA) demonstrating how recent human groups are "closely packed together," with the fossils clustering at the periphery. The results can be interpreted as genetic evolution and speciation or regional adaptation over time to selection pressures. However, another feature appears in his chart, that sex significantly separates the results of Australian males and females widely distinguished, as are recent white and African-American males and females and Inuit males and females. Some exceptions are also present, Sami males and females and Khoisan. These interpretations seem arbitrary, so how to we regard the findings, especially the sex differences? Is gender a factor influencing all the charts, especially those based on small samples?

As I have mentioned in an earlier paper (2016) we are limited in our understanding of hybridization in paleospecies, but some, as in the case of Clifford Jolly, have discussed hybridization in other contexts in primates, as with Papio (Jolly, et al., 1997). Sankararman, et al., (2014) have made a number of suggestions regarding Neandertal and Modern Human sterility based on the current aDNA recovery and sequencing of the $\mathrm{X}$ chromosome. Jagoda, et al. (2018) have recently discovered patterns of positive selection in selective sweeps after "introgression" of archaic genes in anatomically modern humans. As the discovery of Neandertal 
DNA in modern human populations today (Vernot, et al., 2014) disproved earlier arguments for a lack of such transmission (e.g., Krings, et al., 1999), it is likely speculations by Sankaraman et al., (2014) will be unsupported in the future. Ideas of hominid hybrids, especially hybridization and speciation formulas are often based on concepts of narrow clines (Rouhani, 1989) but humans have been widely dispersed species for millions of years and ethnohistorical evidence indicates that even where there is ritual violence and avoidance among groups, there is often bride exchange. Herdt, (2003) and Munir, and Akhtar, (2014), provide examples of recent and hostile groups even today. Arguments of isolation of populations in the mid Pleistocene and speciation are undermined by "exceptions" of gene transmission that keep appearing, as recently in Central African Pygmies (Hsieh, et al., 2016). This idea is supported by findings that admixture has been prevalent throughout human history (Mallick, 2016). Variations in gene frequencies among populations can be associated with demographic expansion of some versus others (Excoffier, and Schneider, 1999). However, as the demographic history of human populations and the rate of expansion is unknown, it seems unwise to set an arbitrary factor for the entire history of humanity. French (2015) has shown that proxies for demographic change produce conflicting results. Questions of admixture and gene evolution following migrations from Africa present problems in the HLA immune system genes where variants in Khoisan and pygmy populations and other moderns are in contradiction. However, some Denisovan variants HLA-A-C in *11, for example, show considerable identity and due to their rapid evolution create problems for simple models (Abi-Rached, et a., 2011).

The problem with behavior differences has been significant in determining the transition to sapiens status. Emphasis on toolmaking and especially the theories of speciation associated with "advanced" blade industries lose their force when early Australian tool kits are examined 
(Mellars \& Stringer, 1989). The very fact that the simple tools used by the first Australians had served them (and their ancestors) well in crossing not only the vast territories and varied environments from Africa to South Asia and had been sufficient to cross the sea barrier to Australia itself is notable. It was their ability to create tools and to use them in adaptive ways and not the tools alone that made the difference. This points out the fallacy of using technology to define species.

\section{Association and Not Causation}

As discussed above for haplotypes, disease and origin, genetic studies of ability have confused association of SNPs with causation of ability. Some of these efforts to parse out the factors of IQ have turned to Meta studies, looking at large groups of data derived from specific surveys of both adults and children. They search the studies for potential markers of biologically determined ability. Others collect responses from populations they create from available sources and manipulate the populations to fit certain criteria of their study, for example, the availability of genetic data. The study by Benyamin, et al, (2014) is one of these, they focused on the FNBP1L gene and used data available from a number of pre-existing sources from which genetic data was available.

Their sample contained 17,989 children of European ancestry and they purged it of outliers due to "missingness" heterozygosity, relatedness, population and ethnic outliers and other undefined cohort-specific quality control steps. Most of the studies they utilized were not random samples. For example, The Avon Longitudinal Study of Parents and Children, was collected from mothers having multiple pregnancies or two births between 1991 and 1992, thus it is a select population and not a random sample. The authors state that they found that, "There 
was no SNP that reached nominal significance after a Bonferroni adjustment." This is a statistical test to ensure that when multiple comparisons or multiple hypotheses are tested the chance of a rare event increases, and therefore, the likelihood of incorrectly rejecting a null hypothesis (a Type One error) increases. This method is named after the Italian mathematician, Carlo Emilio Bonferroni, but it was standardized by the work of Olive Jean Dunn (Dunn, 1959). The authors meta-analyzed their data from the cohorts and found there were no SNPs that reached a genome-wide significant threshold. However, when plotting the estimated regression coefficients from the top 100 SNPs between their samples they found a positive correlation and identified FNBPIL (formin binding protein I-like) as associated with childhood intelligence.

Two main problems with studies like this are (1) the idea that one factor can be the causative agent and its effects controlled, and the fallacy that association equals causation. If we ask the question of what does FNBPIL do, we find a rather disappointing answer. This is a protein of the BAR Domain Superfamily of proteins. These are involved in endocytosis and cell migration. This class of proteins remains evolutionarily conserved from yeast to human. The amino acid sequence of the F-BAR domain of Toca-1/formin binding protein 1-like (FNBPIL) is almost identical to those of CIP4 and FBPI7. These latter two are involved in the diameter of tubules, correspond to the curvature of the initial stages of clathrin-coated pits and CIP4 regulates insulin signaling, the F-BAR and SH3 domains of FBP17 and they are essential for the formation of podosome and phagocytic cups in macrophages. Additionally, Toca-1/FNBPIL is essential for autophagy of the intracellular pathogen Salmonella enterica serovar Typhimurium (Safari and Suetsugu, 2012) and we can go on. In other words, this protein which they have attempted to associate with intelligence is involved in so many biochemical interactions in the body that it is surprising that they would isolate it as a causative agent in a capacity such as 
intelligence without defining a role specific to the quality. However, this tendency is characteristic of other such studies of intelligence using SNPs, such as those by Davies, et al., (2011). Scott (1989) described the limits of single gene focus in his comprehensive work on systems in biology. Such mistaken ideas of single gene expression fail to understand the nature of transcriptional activity of alleles, as in the case of mono or biallelic expression (Gimelbrant, et al., 2007). Yet resolution in branch studies of phylogenetic studies often rests on single gene influences and when in concatenation analyses removal of some genes this can create spurious relationships even in the resolution of large data sets (Shen, et al., 2017).

Furthermore, another consideration, that of Linkage Disequilibrium (LD). A recent study by Koch, et al. (2013) demonstrated an excess of associations between pairs of distant sites on all of the 22 autosomes. It is clear that "detecting" LD does not ensure linkage or a lack of equilibrium. LD has generally been defined as an association between pairs of sites or loci, yet Koch, et al. (2013) argues that there seems to be associations between pairs of chromosome blocks separated by large intervening chromosome regions, referred to as Long-range linkage disequilibria (LRLD). Several types of confounding data problems exist including, miscalled SNPs and phasing errors. Another factor is LD decay and its variation (Vos, et al., 2017).

Assumptions alone are not the only problem with claimed associations. In the initial work conducted by Stoneking and Cann (e.g., 1989) they produce a figure (2.1) where they claim “...the average sequence divergence that has accumulated since the common mtDNA ancestor is $0.57 \% . . . "$ however, when one looks at the data we find that it represents groups with numbers of individuals in the groups ranging from 134 to 21 . They have weighted all these groups equally though they vary in sequence divergence from 0.00 in the Venezuela sample to 0.59 among the San. The sample with the largest number of individuals, the Sardinians at 134, has one of the 
lowest rates or 0.29 . The median rate of all the individuals provided is 0.32 which would substantially change their date of separation. Also, it is unclear if the estimations of mtDNA mutation rates are clearly understood. Parsons, et al. (1997) found higher rates than are generally recognized today. Most rates are based on the idea that paternal mtDNA never enters the ovum and never contributes to the fertilized cell. There has been clear evidence this is false given the demonstration published by Aitken (1995) and Ankel-Simons and Cummins (1996). Further

evidence of this "paternal leakage" is found in sheep (Zhao, et al., 2004) and humans (Schwartz and Vissing, 2002; Guo, et al., 2013). To date no one has conducted a comprehensive study of such transmission across populations. However, Pyle, et al. (2015) question reports of paternal mtDNA inheritance. Assumptions that mtDNA variations are neutral are also at odds with the biology of mtDNA in vertebrates (Caldararo \& Guthrie, 1998). To reduce problems in control region studies, Ingman, et al., (2000) produced a study of the entire mtDNA genome of a larger sample than most researchers.

\section{Conclusions: Over Extension and Futures}

While the technology of ancient DNA extraction, processing, and preservation has increased dramatically in the past 40 years, our ability to interpret the results remains in the developmental stage. Models and simulations of how specific sequences might have been transmitted across the globe and promoted survival or been selected against have produced contradictory results. On the other hand, agreement of nuclear DNA, mtDNA and Y-chromosome DNA and even linguistic evolution (Cavalli-Sforza, Minch \& Mountain, 1992; Skoglund, et al., 2018, Kusuma, et al, 2015; but compare, Roewer, et al., 2013) would seem to set the issue to rest. Yet if one looks closer, the manipulation of data sets and the application of more complicated models and 
statistical processing, could also explain convergence of these different DNA sets. There is nothing sinister in this, people look for what is expected and feel comfortable to discover it. The way data is discovered and interpreted gives it a certain structure, as in the simple case with hominin discoveries shown in Table 1, or as data is processed with new methods as we find today with "algorithm bias" (Murgia, 2019). Perhaps this is what we should have expected, not just because the writing of an algorithm must be based on a certain understanding of prior information on a subject, and on past histories of patterns of events; but because, in the case of hominin evolution, selection has changed over time. Selection pressures 2 million years ago were obviously different that those today. Some traits that were adaptive then lost their benefits for survival. This occurred due in part to migrations into new territories (less solar radiation and less need for melanin in the skin the loss of which can promote bone growth but also be a factor associated with disease like hypervitaminosis and Multiple Sclerosis, (see Caldararo \& Gabow, 2000). Trade-offs in mutations, silencing of genes, polygenic effects, and duplications have created new complex interaction with the environment and plants and animals. New ecological systems are created and humans have become substrates for new and old pathogens and symbionts. An algorithm developed to account for factors of environment and selection today can hardly be expected to pattern accurately selective pressures of the distant past without knowledge and characterization of these factors.

Alternatively, our attempts to use math to construct computer approaches to human conditions (algorithms) to model trends over time can be compared with the human genome's attempt to produce genetic responses to improve the survival of its gene-machine (in Dawkin's [1989] sense here). Thus haplotypes are really nature's algorithms based on past responses in the biosphere for the hominins of the time, for example, the immune/pathogen co-evolutionary 
history (Caldararo, 1996). Eventually, new techniques will bring us closer to an understanding of the relationships of paleospecies representing human evolution.

We find the idea of the DNA code continues to stimulate new frontiers of research and commerce, some of it very concerning, such as the potential for data leaks of sensitive information, loss of anonymity, and in the identification of people in data bases, or uncovering potential risks for corporate health care or life insurance. Other concepts are simply as odd as revealing ancient past ethnicities, such as in "DNA menus" provided by Life Genetics (http://lifegenetics.net/1-click-dna-menu-planning/) or "DNA Pizza" (http://www.dnapizza.com/menu.html). Public awareness of problems with these claims is spreading and could undermine public confidence in DNA studies in general (Bridge, 2018).

Much progress has been made since Mayr's (1963) corrections to classification, and yet many of the problems we still address were anticipated by Lotka in 1926 in applying math to biology. Finally, our physiology does change in the lifetime of individuals, some changes are related to aging but our samples do not reflect these variations (e.g., Dekaban and Sadowsky, 1978; Schultz, 1950). Trait variation in a species defines the adaptations of the species to conditions over time and reflects the success and failure of those traits. However, variation per se does not equate the creation of new species as Washburn (1963) so clearly argued. The delusion of constantly attempting to identify differences (especially in definitions of synapomorphies) has a disgraced history in ideas of racial formation which typified Physical Anthropology of the $19^{\text {th }}$ and early $20^{\text {th }}$ centuries. We should strive to interpret variations in the context of population diversity and adaptation while recognizing variation is constant but not always the road to speciation.

Already new interpretations of hominin fossil materials and genetics are being produced Pre-print version. Visit http://digitalcommons.wayne.edu/humbiol/ after publication to acquire the final version. 
and show similar perspectives to those presented in this article (Bae, Douka and Petraglia, $2017 \mathrm{a} \& \mathrm{~b})$. Hopefully our picture of human origins will continue to evolve as new methods and new discoveries of fossils continue to appear and add to our knowledge and interpretation.

\section{Acknowledgements}

I must thank Dr. Michelle Kaye Fitzgerald for her careful edit of my paper. She gave the text a degree of readability I only could hope for achieving.

Received 14 September 2018; accepted for publication 10 March 2019.

Pre-print version. Visit http://digitalcommons.wayne.edu/humbiol/ after publication to acquire the final version. 


\section{Literature Cited}

Abi-Rached, L., M. J. Jobin, S. Kulkarni et al. 2011. The shaping of modern human immune system by multiregional admixture with archaic humans. Science 334:1-8.

Aitken, R. J. 1996. The complexities of conception. Science 269:39-40.

An, Y., K. L. Furber, and S. Ji. 2017. Pseudogenes regulate parental gene expression via ceRNA network. J. Cell. Mol. Med. 21:185-192.

Ankel-Simons, F., and J. M. Cummins. 1996. Misconceptions about mitochondria and mammalian fertilization: implications for theories on human evolution. Proc. Natl. Acad. Sci. U. S. A. 93:13,859-13,863.

Aubert, M., P. Setiawan, A. A. Oktaviana et al. 2018. Palaeolithic cave art in Borneo. Nature $564: 254-257$.

Audano, P. A., A. Sulovari, T. A. Graves-Lindsay et al. 2019. Characterizing the major structural variant alleles of the human genome. Cell 176:663-675.

Avise, J. C., D. Walker, and G. C. Johns. 1998. Speciation durations and Pleistocene effects on vertebrate phylogeography. Proc. R. Soc. Lond. B. Biol. Sci. 265:1,707-1,712.

Bae, C. J., K. Douka, and M. D. Petraglia, 2017. On the origin of modern humans: Asian perspectives. Science 358:1-7.

Baldwin, J. M. 1902. Development and Evolution. New York: Macmillan.

Bandelt, H.-J., A. Salas, R. W. Taylor et al. 2009. Exaggerated status of "novel" and "pathogenic" mtDNA sequence variants due to inadequate database searches. Hum. Mutat. 30:191-196.

Benyamin, B., B. Pourcain, O. S. Davis et al. 2014. Childhood intelligence is heritable, highly polygenic and associated with FNBP1L. Mol. Psychiatry 19:253-258.

Pre-print version. Visit http://digitalcommons.wayne.edu/humbiol/ after publication to acquire the final version. 
Berger, L. R, S. E. Churchill, B. De Klerk et al. 2008. Small-bodied humans from Palau, Micronesia. PLoS One 3:e1780.

Berger, L. R., J. Hawks, D. J. de Ruiter et al. 2015. Homo naledi, a new species of the genus Homo from the Dinaledi Chamber, South Africa. Elife 4.

Bergman, T. J., and J. C. Beehner. 2004. Social system of a hybrid baboon group (Papio anubis $\times$ P. hamadryas). Int. J. Primatol. 25:1,313-1,330.

Berry, R. J. 1964. The evolution of an island population of the house mouse. Evolution 18:468483.

Berry, R. J., I. M. Evans, and B. F. C. Sennitt. 1967. The relationships and ecology of Apodemus sylvaticus from the Small Isles of the Inner Hebrides, Scotland. J. Zool. 152:333-346.

Berry, A. C., R. J. Berry, and P. J. Ucko. 1967. Genetical change in ancient Egypt. Man 2:551568.

Bizon, C., M. Spiegel, S. A. Chasse et al. 2014. Variant calling in low-coverage whole genome sequencing of a Native American population sample. BMC Genomics 15:85.

Blalock, H. M., Jr. 1960. Social Statistics. New York: McGraw-Hill.

Blinkov, S. M., and I. I. Glezer. 1968. The Human Brain in Figures and Tables: A Quantitative Handbook. New York: Plenum Press.

Boaz, N. T. 1979. Early hominid population densities: New estimates. Science 206:592-595.

Brace, C. L. 1981. Tales of the phylogenetic woods: The evolution and significance of evolutionary trees. Am. J. Phys. Anthropol. 56:411-429.

Bridge, M., and A. Ellson. 2018. Privacy fears over 'flawed' DNA tests. The Times, June 16, 2018. https://www.thetimes.co.uk/article/privacy-fears-over-flawed-dna-tests-spcxscw83.

Brothwell, D. R. 1959. The use of non-metrical characters of the skull in differentiating 
populations. Dt. Ges. Anthrop. 6:103-109.

Brothwell, D. R. 1961. The biology of earlier human populations. In Science in Archaeology, D. R. Brothwell and E. Higgs, eds. London: Thames \& Hudson, 330-341.

Brunetti-Pierri, N., J. S. Berg, F. Scaglia et al. 2008. Recurrent reciprocal 1q21.1 deletions and duplications associated with microcephaly or macrocephaly and developmental and behavioral abnormalities. Nat. Genet. 40:1,466-1,471.

Burman, J. T. 2013. Updating the Baldwin effect: The biological levels behind Piaget's new theory. New Ideas Psychol. 31:363-373.

Bush, G. L., S. M. Case, A. C. Wilson et al. 1977. Rapid speciation and chromosomal evolution in mammals. Proc. Natl. Acad. Sci. U. S. A. 74:3,942-3,946.

Battistuzzi, F. U., A. J. Filipski, and S. Kumar. 2011. Molecular clock: Testing. eLS. doi: 10.1002/9780470015902.a0001803.pub2.

Caldararo, N. 1996. The HIV/AIDS epidemic: Its evolutionary implications for human ecology with special reference to the immune system. Sci. Total Environ. 191:245-269.

Caldararo, N., and S. Gabow. 2000. Mitochondrial DNA analysis and the place of Neandertals in Homo. Anc. Biomol. 3:135-158.

Caldararo, N., and M. Guthrie. 1998. Mitochondrial DNA, the Y chromosome and the origins of modern humans. HOMO 49:225-240.

Caldararo, N., and M. Guthrie. 2012. A note on the Denisova cave mtDNA sequence. Nature Precedings. doi: 10.1038/npre.2012.5360.4.

Caldararo, N. 2005. Hair, human evolution, and the idea of human uniqueness. Evol. Anthropol. 14:132-133. 
Caldararo, N. 2016. Denisovans, Melanesians, Europeans, and Neandertals: The confusion of DNA assumptions and the biological species concept. J. Mol. Evol. 83:78-87.

Caldararo, N. L. 2017. Big Brains and the Human Superorganism: Why Special Brains Appear in Humans and Other Social Animals. Lanham, MD: Lexington Press.

Callaway, E. 2016. Error found in study of first ancient African genome. Nature, January 29, 2016. doi: 10.1038/nature.2016.19258.

Cameron, N. M. 2011. Maternal programming of reproductive function and behavior in the female rat. Front. Evol. Neurosci. 3:1-10.

Carroll, S. B. 1995. Homeotic genes and the evolution of arthropods and chordates. Nature $376: 479-485$.

Cavalli-Sforza, L. L., E. Minch, and J. L. Mountain. 1992. Coevolution of genes and languages revisited. Proc. Natl. Acad. Sci. U. S. A. 89:5,620-5,624.

Charrier, C., K. Joshi, J. Coutinho-Budd et al. 2012. Inhibition of SRGAP2 function by its human-specific paralogs induces neoteny during spine maturation. Cell 149:923-935.

Cheney, D. L., and R. M. Seyfarth. 2007. Baboon Metaphysics. Chicago, IL: University of Chicago Press.

Cheverud, J. M. 1988. A comparison of genetic and phenotypic correlations. Evolution 42:958968.

Choudhury, M. N., and S. Chakraborty. 2015. Codon usage pattern in human SPANX genes. Bioinformation 11:454-459.

Conn, P. B, D. S. Johnson, J. M. Ver Hoef et al. 2015. Using spatiotemporal statistical models to estimate animal abundance and infer ecological dynamics from survey counts. Ecol. Monogr. 85:235-252.

Pre-print version. Visit http://digitalcommons.wayne.edu/humbiol/ after publication to acquire the final version. 
Crisp, A., C. Boschetti, M. Perry et al. 2015. Expression of multiple horizontally acquired genes is a hallmark of both vertebrate and invertebrate genomes. Genome Biol. 16:1-13.

Crow, D. 2017. Vein-to-vein solutions. Financial Times, June 13, 2017.

Darwin, C. 1989. Charles Darwin's Notebooks, 1836-1844: Geology, Transmutation of Species, Metaphysical Enquiries. P. H. Barrett, P. J. Gautrey, S. Herbert, D. Kohn, and S. Smith, eds. Ithaca, NY: Cornell University Press.

Davidson, J. 1984. The Prehistory of New Zealand. Auckland, New Zealand: Longman Paul.

Davis-Dao, C. A., E. D. Tuazon, R. Z. Sokol et al. 2007. Male infertility and variation in CAG repeat length in the androgen receptor gene: A meta-analysis. J. Clin. Endocrinol. Metab. 92:4,319-4,326.

Davies, G., A. Tenesa, A. Payton et al. 2011. Genome-wide association studies establish that human intelligence is highly heritable and polygenic. Mol. Psychiatry 16:996-1,005.

Dawkins, R. 1999. The Extended Phenotype. Oxford, UK: Oxford University Press.

Dawkins, R. 1989. The Selfish Gene, second edition. Oxford, UK: Oxford University Press.

Deacon, T. W. 1997. The Symbolic Species. New York: W.W. Norton.

Dekaban, A. S., and D. Sadowsky. 1978. Changes in brain weights during span of human life: Relation of brain weights to body heights and body weights. Ann. Neurol. 4:345-356.

Dembo, M., N. J. Matzke, A. Ø. Mooers et al. 2015. Bayesian analysis of a morphological supermatrix sheds light on controversial fossil hominin relationships. Proc. Biol. Sci. 282:1-9.

Dennis, M. Y, X. Nuttle, P. H. Sudmant et al. 2012. Evolution of human-specific neural SRGAP2 genes by incomplete segmental duplication. Cell 149:912-922.

D'Errico, F. 2003. The invisible frontier. A multiple species model for the origin of behavioral 
modernity. Evol. Anthropol. 12:189-202.

DeSilva, J. M., and J. J. Lesnik. 2008. Brain size at birth throughout human evolution: A new method for estimating neonatal brain size in hominins. J. Hum. Evol. 55:1,064-1,074.

Détroit, F., A. S. Mijares, J. Corny et al. A new species of Homo from the Late Pleistocene of the Philippines. Nature 568:181-186.

Diamond, M. C. 1988. Enriching Heredity: The Impact of the Environment on the Anatomy of the Brain. New York: Free Press.

Díaz-Uriarte, R., and T. Garland Jr. 1996. Testing hypotheses of correlated evolution using phylogenetically independent contrasts: sensitivity to deviations from Brownian Motion. Syst. Biol. 45:27-47.

Dobzhansky, T. 1944. On the species and races of living and fossil man. Am. J. Phys. Anthropol. $2: 251-265$.

Domes, K., R. A. Norton, M. Maraun et al. 2007. Reevolution of sexuality breaks Dollo’s law. Proc. Natl. Acad. Sci. U. S. A. 104:7,139-7,144.

Dumas, L. J., M. S. O’Bleness, J. M. Davis et al. 2012. DUF1220-domain copy number implicated in human brain-size pathology and evolution. Am. J. Hum. Genet. 91:444454.

Dunn, O. J. 1959. Confidence intervals for the means of dependent, normally distributed variables. J. Am. Stat. Assoc. 54:613-621.

Durbin, R., S. Eddy, A. Krogh, and G. Mitchison. (1998) 2013. Biological Sequence Analysis: Probabilistic Models of Proteins and Nucleic Acids. Cambridge, UK: Cambridge University Press. 
Earnest, A., and D. Wang. 2012. Health and the Huaorani. The Yale Review of International Studies. August 2012. http://yris.yira.org/essays/597.

Efron, B. 1979. Bootstrap methods: Another look at the jackknife. Ann. Stat. 7:1-26.

Eldredge, N., and J. Cracraft. 1980. Phylogenetic Patterns and the Evolutionary Process: Method and Theory in Comparative Biology. New York: Columbia University Press.

El Khoury, M., J. Braga, J. Dumoncel et al. 2014. The human semicircular canals orientation is more similar to the bonobos than to the chimpanzees. PLoS One 9:e93824.

Enard, D., and D. A. Petrov. 2018. Evidence that RNA viruses drove adaptive introgression between Neanderthals and modern humans. Cell 175:360-371.

Excoffier, L., and S. Schneider. 1999. Why hunter-gatherer populations do not show signs of Pleistocene demographic expansions. Proc. Natl. Acad. Sci. U. S. A. 96:10,597-10,602.

Felsenstein, J., S. Sawyer, and R. Kochin. 1982. An efficient method for matching nucleic acid sequences. Nucleic Acids Res. 10:133-139.

Firmin, A. (1885) 2002. The Equality of the Human Races. Champaign, IL: University of Illinois Press.

Fišer Pečnikar, Ž., and E. V. Buzan. 2014. 20 years since the introduction of DNA barcoding: From theory to application. J. Appl. Genet. 55:43-52.

Fitch, W. M. 1971. Toward defining the course of evolution: Minimum change for a specific tree topology. Syst. Zool. 20:406-416.

Fitch, W. M. 1977. On the problem of discovering the most parsimonious tree. Am. Nat. 111:223-257.

Fix, A. G. 1999. Migration and Colonization in Human Microevolution. Cambridge, UK: Cambridge University Press. 
Freckleton, R. P., P. H. Harvey, and M. Pagel. 2002. Phylogenetic analysis and comparative data: A test and review of evidence. Am. Nat. 160:712-726.

French, J. C. 2015. The demography of the Upper Palaeolithic hunter-gatherers of Southwestern France: A multi-proxy approach using archaeological data. J. Anthropol. Archaeol. 39:193-209.

Ghafouri-Fard, S., M. Fardaei, M. Gholami et al. 2015. A case report: Autosomal recessive microcephaly caused by a novel mutation in MCPH1 gene. Gene 571:149-150.

Gimelbrant, A., J. N. Hutchinson, B. R. Thompson et al. 2007. Widespread monoallelic expression on human autosomes. Science 318:1,136-1,140.

Gokcumen, O. 2018. The year in genetic anthropology: New lands, new technologies, new questions. Am. Anthropol. 120:266-277.

Gould, S. J. 1996. Full House: The Spread of Excellence. New York: Harmony Press.

Gould, S. J. 1996a. The Mismeasure of Man. New York: W.W. Norton.

Grewal, M. S. 1962. The rate of genetic divergence of sublines in the C57BL strain of mice. Genet. Res. Camb. 3:226-237.

Groeneveld, H. T., and J. A. Kieser. 1987. An evaluation of the M-statistic in human odontomorphometric distance analyses. Int. J. Anthropol. 2:29-36.

Guo, Y., C. I. Li, Q. Sheng et al. 2013. Very low-level heteroplasmy mtDNA variations are inherited in humans. J. Genet. Genomics 40:607-615.

Haig, D. 2007. Weismann rules! OK? Epigenetics and the Lamarckian temptation. Biol. Philos. $22: 415-428$. 
Haile-Selassie, Y. 2010. Phylogeny of early Australopithecus: New fossil evidence from the Woranso-Mille (central Afar, Ethiopia). Philos. Trans. R. Soc. Lond. B. Biol. Sci. $365: 3,323-3,331$.

Haws, D. C., T. L. Hodge, and R. Yoshida. 2011. Optimality of the Neighbor Joining algorithm and faces of the balanced minimum evolution polytope. Bull. Math. Biol. 73:2,627-2,648.

Hay, M. 2017. Origins, spread and ethnic association of European haplogroups and subclades. Eupedia, August 2017. https://www.eupedia.com/europe/origins_haplogroups_europe.shtml.

Henneberg, M., R. B. Eckhardt, S. Chavanaves et al. 2014. Evolved developmental homeostasis disturbed in LB1 from Flores, Indonesia, denotes Down syndrome and not diagnostic traits of the invalid species Homo floresiensis. Proc. Natl. Acad. Sci. U. S. A. 111:11,967-11,972.

Herculano-Houzel, S. 2016. The Human Advantage. Cambridge, MA: MIT Press.

Herdt, G. 2003. Secrecy and Cultural Reality: Utopian Ideologies of the New Guinea Men's House. Ann Arbor, MI: University of Michigan Press.

Hess, L. 1945. The metopic suture and the metopic syndrome. Hum. Biol. 17:107-136.

Heyman, K. 2005. Gene finding with hidden Markov models. The Scientist, March 28, 2005. https://www.the-scientist.com/technology/gene-finding-with-hidden-markov-models48914.

Heyman, K. 2005. Retroelements guide adaptation. The Scientist, January 31, 2005. https://www.the-scientist.com/research/retroelements-guide-adaptation-49109.

Holloway, R. L. 1980. Within-species brain-body weight variability: A reexamination of the Danish data and other primate species. Am. J. Phys. Anthropol. 53:109-121. 
Holloway, R. 1996. Evolution of the human brain. In Handbook of Human Symbolic Evolution,

A. Lock and C. Peters, eds. New York: Oxford University Press, 74-116.

Hooton, E. A. 1946. Up from the Ape. New York: Macmillan.

Houghton, P. 1980. The First New Zealanders. Auckland, New Zealand: Hodder and Stoughton.

Howe, W. L., and P. A. Parsons. 1967. Genotype and environment in the determination of minor skeletal variants and body weight in mice. J. Embryol. Exp. Morphol. 17:283-292.

Howell, F. C. 1996. Thoughts on the study and interpretation of the human fossil record. In Contemporary Issues in Human Evolution, W. E. Meikle, F. C. Howell, and N. G. Jablonski, eds. San Francisco: California Academy of Sciences, 1-45.

Howells, W. W. 1959. Mankind in the Making. Garden City, NY: Doubleday.

Howells, W. W. 1973. Cranial Variation in Man: A Study by Multivariate Analysis of Patterns of Differences among Recent Human Populations. Cambridge, MA: Peabody Museum.

Howells, W. W. 1989. Skull Shapes and the Map: Craniometric Analyses in the Dispersion of Modern Homo. Cambridge, MA: Peabody Museum.

Hsieh, P., A. E. Woerner, J. D. Wall et al. 2016. Model-based analyses of whole-genome data reveal a complex evolutionary history involving archaic introgression in Central African Pygmies. Genome Res. 26:291-300.

Hublin, J.-J., A. Ben-Ncer, S. E. Bailey et al. 2017. New fossils from Jebel Irhoud, Morocco and the pan-African origin of Homo sapiens. Nature 546:289-292.

Hubbe, M., and W. A. Neves. 2007. On the Misclassification of human crania: Are there any implications for assumptions about human variation? Curr. Anthropol. 48:285-288.

Humphrey, N., J. R. Skoyles, and R. Keynes. 2005. Human hand-walkers: Five siblings who never stood up. London: LSE Research Online. http://eprints.lse.ac.uk/463/. 
Ingman, M., H. Kaessmann, S. Pääbo et al. 2000. Mitochondrial genome variation and the origin of modern humans. Nature 408:708-713.

Jagoda, E., D. J. Lawson, J. D. Wall et al. 2018. Disentangling immediate adaptive introgression from selection on standing introgressed variation in humans. Mol. Biol. Evol. 35:623630.

Jolly, C. J., T. Woolley-Barker, S. Beyene et al. 1997. Intergeneric hybrid baboons. Int. J. Primatol. 18:597-627.

Jukes, T. H., and C. R. Cantor. 1969. Evolution of protein molecules. In Mammalian Protein Metabolism, volume III, H. N. Munro, ed. New York: Academic Press, 21-132.

Kane, J. “Savages.” San Francisco Examiner, October 29, 1995.

Kern, A. D., and M. H. Hahn. 2018. The neutral theory in light of natural selection. Mol. Biol. Evol. 35:1,366-1,371.

Keynes, J. M. 1921. A Treatise on Probability. London: Macmillan and Co., Ltd.

Kimbel, W. H., C. A. Lockwood, C. V. Ward et al. 2006. Was Australopithecus anamensis ancestral to A. afarensis? A case of anagenesis in the hominin fossil record. J. Hum. Evol. $51: 134-152$.

Kimchi-Sarfaty, C., A. H. Marple, S. Shinar et al. 2007. Ethnicity-related polymorphisms and haplotypes in the human ABCB1 gene. Pharmacogenomics 8:29-39.

Klein, R. J., Z. Misulovin, and S. R. Eddy. 2002. Noncoding RNA genes identified in AT-rich hyperthermophiles. Proc. Natl. Acad. Sci. U. S. A. 99:7,542-7,547.

Koch, E., M. Ristroph, and M. Kirkpatrick. 2013. Long range linkage disequilibrium across the human genome. PLoS One 8:e80754.

Krantz, G. S. 1961. Pithecanthropine brain size and its cultural consequences. Man 61:85-87. 
Krings, M., H. Geisert, R. W. Schmitz et al. 1999. DNA sequence of the mitochondrial hypervariable region II from the Neandertal type specimen. Proc. Natl. Acad. Sci. U.S. A. $96: 5,581-5,585$.

Kruska, D. C. T. 2007. The effects of domestication on brain size. In Evolution of Nervous Systems, J. H. Kaas, ed. Cambridge, MA: Academic Press, 143-153.

Kubatko, L. S., and J. H. Degnan. 2007. Inconsistency of phylogenetic estimates from concatenated data under coalescence. Syst. Biol. 56:17-24.

Kubo, D., R. T. Kono, and Y. Kaifu. 2013. Brain size of Homo floresiensis and its evolutionary implications. Proc. R. Soc. Lond. B Biol. Sci. 280:1-8.

Kusuma, P., M. P. Cox, D. Pierron et al. 2015. Mitochondrial DNA and the Y chromosome suggest the settlement of Madagascar by Indonesian sea nomad populations. BMC Genomics 16:191.

Kutzner, A., S. Pramanik, P.-S. Kim et al. 2015. All-or-(N)One-An epistemological characterization of the human tumorigenic neuronal paralogous FAM72 gene loci. Genomics 106:278-285.

Lamarck, J.-B. 1830. Philosophie zoologique. Paris: G. Baillière.

Laughlin, W. S., and J. B. Jørgensen. 1956. Isolate variation in Greenlandic Eskimo crania. Acta Genet. Stat. Med. 6:3-12.

Le Gros Clark, W. E. 1934. Early Forerunners of Man: A Morphological Study of the Evolutionary Origins of the Primates. Oxford, UK: Oxford University Press.

Le Gros Clark, W. E. 1964. The Fossil Evidence for Human Evolution, Revised Edition. Chicago, IL: University of Chicago Press.

Lewin, R. 1989. Species questions in modern human origins. Science 243:1,666-1,667. 
Lewis-Kraus, G. 2019. Is ancient DNA research revealing new truths—or falling into old traps? New York Times, January 17, 2019. https://www.nytimes.com/2019/01/17/magazine/ancient-dna-paleogenomics.html.

Li, W.-H., and D. Graur. 1991. Fundamentals of Molecular Evolution. Sunderland, MA: Sinauer Associates.

Libiger, O., C. M. Nievergelt, and N. J. Schork. 2009. Comparison of genetic distance measures using human SNP genotype data. Hum. Biol. 81:389-406.

Lieberman, D. E. 2009. Homo floresiensis from head to toe. Nature 459:41-42.

Lordkipanidze, D., M. S. Ponce de León, A. Margvelashvili et al. 2013. A complete skull from Dmanisi, Georgia, and the evolutionary biology of early Homo. Science 342:326-331.

Lotka, A. J. 1956. The Elements of Mathematical Biology. Mineola, NY: Dover Publications. Lovejoy, C. O., and E. Trinkaus. 1980. Strength and robusticity of the Neandertal tibia. Am. J. Phys. Anthropol. 53:465-470.

Lowenstein, J. M. 1999. Evolutionary information from fossil molecules. In The New Physical Anthropology: Science, Humanism and Critical Reflection, S. C. Strum, D. G. Lindburg, and D. Hamburg, eds. Upper Saddle River, NJ: Prentice Hall, 174-180.

Lu, Z.-X., J. Peng, and B. Su. 2007. A human-specific mutation leads to the origin of a novel splice form of neuropsin (KLK8), a gene involved in learning and memory. Hum. Mutat. 28:978-984.

Magosi, L. E, A. Goel, J. C. Hopewell et al. 2017. Identifying systematic heterogeneity patterns in genetic association meta-analysis studies. PLoS Genet. 13:e1006755.

Mallick, S., H. Li, M. Lipson et al. 2016. The Simons Genome Diversity Project: 300 genomes from 142 diverse populations. Nature 538:201-206. 
Margulis, L. 1981. Symbiosis in Cell Evolution: Life and Its Environment on the Early Earth. San Francisco, CA: W. H. Freeman \& Co.

Mayr, E. 1963. Animal Species and Evolution. Cambridge, MA: Belknap Press of Harvard University Press.

Mayr, E. 1970. Populations, Species and Evolution: An Abridgement of Animal Species and Evolution. Cambridge, MA: Belknap Press of Harvard University Press.

Mayr, E. 1982. The Growth of Biological Thought. Cambridge, MA: Belknap Press of Harvard University Press.

Mazumder, G. A, A. Uddin, and S. Chakraborty. 2017. Comparative analysis of codon usage pattern and its influencing factors in Schistosoma japonicum and Ascaris suum. Acta Parasitol. 62:748-761.

Meirmans, P. G. 2012. Trouble with isolation by distance. Mol. Ecol. 21:2,839-2,846.

Mellars, P., and C. Stringer. 1989. Introduction. In The Human Revolution: Behavioural and Biological Perspectives in the Origins of Modern Humans, P. Mellars and C. Stringer, eds. Princeton, NJ: Princeton University Press, 1-16.

Mendez, F. L., J. C. Watkins, and M. F. Hammer. 2012. A haplotype STAT2 introgressed from Neanderthals and serves as a candidate of positive selection in Papua New Guinea. Am. J. Hum. Genet. 91:265-274.

Munir, A., and N. Akhter. 2014. A social custom "Vani": Introduction and critical analysis. VFAST Transactions on Education and Social Science 3:1-4.

Murgia, M. 2019. How to stop computers being biased. Financial Times, February 12, 2019. https://www.ft.com/content/12dcd0f4-2ec8-11e9-8744-e7016697f225. 
Needleman, S. B., and C. D. Wunsch. 1970. A general method applicable to the search for similarities in the amino acid sequence of two proteins. J. Mol. Biol. 48:443-453.

Neubauer, S., J.-J. Hublin, and P. Gunz. 2018. The evolution of modern human brain size. Sci. $A d v .4: 1-8$.

Neufeld, A. H., and G. C. Conroy. 2004. Human head hair is not fur. Evol. Anthropol. 13:89.

Nuzzo, R. 2014. Scientific method: Statistical errors. Nature 506:150-152.

O’Hara, R. J. 1993. Systematic generalization, historical fate, and the species problem. Syst. Biol. 42:231-246.

O’Hara, R. J. 1994. Evolutionary history and the species problem. Am. Zool. 34:12-22.

Pagel, M. 1999. The maximum likelihood approach to reconstructing ancestral character states of discrete characters on phylogenies. Syst. Biol. 48:612-622.

Pardi, F., and C. Scornavacca. 2015. Reconstructible phylogenetic networks: Do not distinguish the indistinguishable. PLoS Comput. Biol. 11:1-23.

Parsons, T. J, D. S. Muniec, K. Sullivan et al. 1997. A high observed substitution rate in the human mitochondrial DNA control region. Nat. Genet. 15:363-368.

Pearson, K. 1901. On lines and planes of closest fit to systems of points in space. Philosophical Magazine 2:559-572.

Pearson, O. M. 2001. Postcranial remains and the origin of modern humans. Evol. Anthropol. 9:229-247.

Penrose, L. S. 1954. Distance, size and shape. Ann. Eugen. 18:337-343.

Perry, G. H., A. Ben-Dor, A. Tsalenko et al. 2008. The fine-scale and complex architecture of human copy-number variation. Am. J. Hum. Genet. 82:685-695. 
Pilcher, H. 2004. Chinese dyslexics have problems of their own. Nature, September 1, 2004. https://www.nature.com/news/2004/040830/full/news040830-5.html.

Puigbò, P., Y. I. Wolf, and E. V. Koonin. 2009. Search for a 'Tree of Life' in the thicket of the phylogenetic forest. J. Biol. 8:1-17.

Pyle, A., G. Hudson, I. J. Wilson et al. 2015. Extreme-depth re-sequencing of mitochondrial DNA finds no evidence of paternal transmission in humans. PLoS Genet. 11:1-11.

Rabosky, D. L., F. Santini, J. Eastman et al. 2013. Rates of speciation and morphological evolution are correlated across the largest vertebrate radiation. Nat. Commun. 4:1-8.

Radhakrishna Rao, C. 1948. The utilization of multiple measurements in problems of biological classification. J. R. Stat. Soc. Series B Stat. Methodol. 10:159-203.

Réale, D., and D. A. Roff. 2001. Estimating genetic correlations in natural populations in the absence of pedigree information: Accuracy and precision of the Lynch method. Evolution $55: 1,249-1,255$.

Reardon, P. K, J. Seidlitz, S. Vandekar et al. 2018. Normative brain size variation and brain shape diversity in humans. Science 360:1,222-1,227.

Reilly, S. K., J. Yin, A. E. Ayoub et al. 2015. Evolutionary changes in promoter and enhancer activity during human corticogenesis. Science 347:1,155-1,159.

Relethford, J. H. 1994. Craniometric variation among modern human populations. Am. J. Phys. Anthropol. 95:53-62.

Relethford, J. H. 2001. Book review: Migration and Colonization in Human Microevolution. Am. J. Hum. Biol. 13:280-296.

Relethford, J. H. 2004. Global patterns of isolation by distance based on genetic and morphological data. Hum. Biol. 76:499-513. 
Ricci, M., V. Peona, E. Guichard et al. 2018. Transposable elements activity is positively related to rate of speciation in mammals. J. Mol. Evol. 86:303-310.

Rightmire, G. P. 1990. The Evolution of Homo erectus: Comparative Anatomical Studies of an Extinct Human Species. Cambridge, MA: Cambridge University Press.

Rishishwar, L., and I. King Jordan. 2017. Implications of human evolution and admixture for mitochondrial replacement therapy. BMC Genomics 18:1-11.

Roewer, L., M. Nothnagel, L. Gusmão et al. 2013. Continent-wide decoupling of Ychromosomal genetic variation from language and geography in Native South Americans. PLoS Genet. 9:1-16.

Roisin, Y., and J. Korb. 2011. Social organization and the status of workers in termites. In Biology of Termites A Modern Synthesis, D. E. Bignell, Y. Roisin, and N. Lo, eds. Dordrecht, Netherlands: Springer, 133-164.

Rokas, A., B. L. Williams, N. King et al. 2003. Genome-scale approaches to resolving incongruence in molecular phylogenies. Nature 425:798-804.

Roseman, C. C. 2004. Detecting interregionally diversifying natural selection on modern human cranial form by using matched molecular and morphometric data. Proc. Natl. Acad. Sci. U. S. A. 101:12,824-12,829.

Rottgardt, I., F. Rothhammer, and M. Dittmar. 2010. Native highland and lowland populations differ in $\gamma$-globin gene promoter polymorphisms related to altered fetal hemoglobin levels and delayed fetal to adult globin switch after birth. Anthropological Science 118:41-48.

Rouhani, S. 1989. Molecular genetics and the pattern of human evolution: Plausible and implausible models. In The Human Revolution: Behavioural and Biological Perspectives in the Origins of Modern Humans, P. Mellars and C. Stringer, eds. Princeton, NJ: 
Princeton University Press, 47-61.

Russell, M. D., T. Brown, S. M. Garn et al. 1985. The supraorbital torus: “A most remarkable peculiarity." Curr. Anthropol. 26:337-360.

Sáez, A. G., and E. Lozano. 2005. Body doubles. Nature 433:111.

Safari, F., and S. Suetsugu. 2012. The BAR domain superfamily proteins from subcellular structures to human diseases. Membranes 2:91-117.

Saitou, N., and M. Nei. 1987. The neighbor-joining method: A new method for reconstructing phylogenetic trees. Mol. Biol. Evol. 4:406-425.

Salichos, L. and A. Rokas. 2013. Inferring ancient divergences requires genes with strong phylogenetic signals. Nature 497:327-331.

Sankararaman, S., S. Mallick, M. Dannemann et al. 2014. The genomic landscape of Neanderthal ancestry in present-day humans. Nature 507:354-357.

Schofield, G. 1959. Metric and morphological features of the femur of the New Zealand Maori. The Journal of the Royal Anthropological Institute of Great Britain and Ireland G. 89:89-105.

Schultz, A. H. 1925. Embryological evidence of the evolution of man. J. Wash. Acad. Sci. 15:247-263.

Schultz, A. H. 1950. The physical distinctions of man. Proc. Am. Philos. Soc. 94:428-449.

Schumacher, J., P. Hoffmann, C. Schmäl et al. 2007. Genetics of dyslexia: The evolving landscape. J. Med. Genet. 44:289-297.

Schwartz, J. H. 1984. The evolutionary relationships of man and orang-utans. Nature 308:501505. 
Schwartz, M., and J. Vissing. 2002. Paternal inheritance of mitochondrial DNA. N. Engl. J. Med. 347:576-580.

Scott, J. P. 1989. The Evolution of Social Systems. New York: Gordon and Breach Science Publishers.

Scuro, S. R. 2004. Introduction to error theory. Technical report, Texas A\&M University.

Sellers, P. H. 1974. On the theory and computation of evolutionary distances. SIAM J. Appl. Math. 26:787-793.

Semple, B. D, K. Blomgren, K. Gimlin et al. 2013. Brain development in rodents and humans: Identifying benchmarks of maturation and vulnerability to injury across species. Prog. Neurobiol. 106-107:1-16.

Sharp, P. M., E. Cowe, D. G. Higgins et al. 1988. Codon usage patterns in Escherichia coli, Bacillus subtilis, Saccharomyces cerevisiae, Schizosaccharomyces pombe, Drosophila melanogaster and Homo sapiens; a review of the considerable within-species diversity. Nucleic Acids Res. 16:8,207-8,211.

Shen, X.-X., C. T. Hittinger, and A. Rokas. 2017. Contentious relationships in phylogenomic studies can be driven by a handful of genes. Nat. Ecol. Evol. 1:0126.

Sherman, R. M., J. Forman, V. Antonescu et al. 2019. Assembly of a pan-genome from deep sequencing 910 humans of African descent. Nat. Genet. 51:30-35.

Shultz, S., and R. I. M. Dunbar. 2010. Social bonds in birds are associated with brain size and contingent on the correlated evolution of life-history and increased parental investment. Biol. J. Linn. Soc. Lond. 100:111-123.

Sims, D., I. Sudbery, N. E. Ilott et al. 2014. Sequencing depth and coverage: Key considerations in genomic analyses. Nat. Rev. Genet. 15:121-132. 
Simpson, G. G. 1944. Tempo and Mode in Evolution. New York: Columbia University Press.

Siok, W. T., C. A. Perfetti, Z. Jin et al. 2004. Biological abnormality of impaired reading is constrained by culture. Nature 431:71-76.

Skoglund, P., C. Posth, K. Sirak et al. 2016. Genomic insights into the peopling of the Southwest Pacific. Nature 538:510-513.

Smith, G. E. 1911. The Ancient Egyptians and Their Influence Upon the Civilization of Europe. London, UK: Harper.

Spoor, F. 2013. Small-brained and big-mouthed. Nature 502:452-453.

Sreelatha, A., S. S. Yee, V. A. Lopez et al. 2018. Protein AMPylation by an evolutionarily conserved pseudokinase. Cell 175:809-821.

Stanhope, M. J, A. Lupas, M. J. Italia et al. 2001. Phylogenetic analyses do not support horizontal gene transfers from bacteria to vertebrates. Nature 411:940-944.

Stoneking, M., and R. L. Cann. 1989. African origin of human mitochondrial DNA. In The Human Revolution: Behavioural and Biological Perspectives in the Origins of Modern Humans, P. Mellars and C. Stringer, eds. Princeton, NJ: Princeton University Press, 1730.

Striedter, G. F. 2005. Principles of Brain Evolution. Sunderland, MA: Sinauer Associates, Inc. Stringer, C. 2012. Lone Survivors: How We Came to Be the Only Humans on Earth. New York: Henry Holt and Company, LLC.

Suárez-Díaz, E., and V. H. Anaya-Muñoz. 2008. History, objectivity, and the construction of molecular phylogenies. Stud. Hist. Philos. Biol. Biomed. Sci. 39:451-468.

Sudmant, P. H., T. Rausch, E. J. Gardner et al. 2015. An integrated map of structural variation in 2,504 human genomes. Nature 526:75-81.

Pre-print version. Visit http://digitalcommons.wayne.edu/humbiol/ after publication to acquire the final version. 
Tan, U. 2006. A new syndrome with quadrupedal gait, primitive speech, and severe mental retardation as a live model for human evolution. Int. J. Neurosci. 116:361-369.

Tattersall, I. 1986. Species recognition in human paleontology. J. Hum. Evol. 15:165-175.

Tattersall, I. 1992. The many faces of Homo habilis. Evol. Anthropol. 1:33-37.

Templeton, A. R. 2005. Haplotype trees and modern human origins. Yearb. Phys. Anthropol. 48:33-59.

Thorne, J. L., H. Kishino, and J. Felsenstein. 1991. An evolutionary model for maximum likelihood alignment of DNA sequences. J. Mol. Evol. 33:114-124.

Tobias, P. V. 1971. The Brain in Hominid Evolution. New York: Columbia University Press. Trinkaus, E. 1990. Cladistics and the hominid fossil record. Am. J. Phys. Anthropol. 83:1-11. van den Bergh, G. D., Y. Kaifu, I. Kurniawan et al. 2016. Homo floresiensis-like fossils from the early Middle Pleistocene of Flores. Nature 534:245-248.

van Oven, M., and M. Kayser. 2009. Updated comprehensive phylogenetic tree of global human mitochondrial DNA variation. Hum. Mutat. 30:E386-E394.

Vernot, B., and J. M. Akey. 2014. Resurrecting surviving Neandertal lineages from modern human genomes. Science 343:1,017-1,021.

Vernot, B., S. Tucci, J. Kelso et al. 2016. Excavating Neandertal and Denisovan DNA from the genomes of Melanesian individuals. Science 352:235-239.

von Bonin, G. 1963. The Evolution of the Human Brain. Chicago, IL: University of Chicago Press.

von Cramon-Taubadel, N. 2014. Evolutionary insights into global patterns of human cranial diversity: Population history, climatic and dietary effects. J. Anthropol. Sci. 92:43-77. 
von Neumann, J. 1951. The general and logical theory of automata. In Cerebral Mechanisms in Behavior: The Hixon Symposium, L. A. Jeffress, ed. New York: John Wiley \& Sons, 141.

Vos, P. G., M. J. Paulo, R. E. Voorrips et al. 2017. Evaluation of LD decay and various LDdecay estimators in simulated and SNP-array data of tetraploid potato. Theor. Appl. Genet. 130:123-135.

Waddington, C. H. 1942. Canalization of development and the inheritance of acquired characters. Nature 150:563-565.

Waddington, C. H. 1956. Principles of Embryology. London, UK: George Allen \& Unwin, Ltd. Wainscoat, J. S., A. V. S. Hill, S. L. Thein et al. 1989. Geographic distribution of Alpha- and Beta-globin gene cluster polymorphisms. In The Human Revolution: Behavioural and Biological Perspectives in the Origins of Modern Humans, P. Mellars and C. Stringer, eds. Princeton, NJ: Princeton University Press, 31-38.

Wallace, D. C. 2015. Mitochondrial DNA variation in human radiation and disease. Cell 163:3338.

Wang, Y., X. Xiao, J. Zhang et al. 2013. A complex network of factors with overlapping affinities represses splicing through intronic elements. Nat. Struct. Mol. Biol. 20:36-45.

Warnow, T. 2017. Computational Phylogenetics: An Introduction to Designing Methods for Phylogeny Estimation. Cambridge, MA: Cambridge University Press.

Washburn, S. L. 1963. The study of race. Am. Anthropol. 65:521-531.

Weaver, I. C. G., N. Cervoni, F. A. Champagne et al. 2004. Epigenetic programing by maternal behavior. Nat. Neurosci. 7:847-854.

Weidenreich, F. 1946. Apes, Giants and Man. Chicago, IL: University of Chicago Press. 
Weidenreich, F. 1947. Facts and speculations concerning the origin of Homo sapiens. Am. Anthropol. 49:187-203.

West, R. J. D. 2014. The evolution of large brain size in birds is related to social, not genetic, monogamy. Biol. J. Linn. Soc. Lond. 111:668-678.

White, T. D. 2000. Human Osteology, second edition. San Diego, CA: Academic Press.

Whitlock, M. C., and F. Guillaume. 2009. Testing for spatially divergent selection: Comparing $Q_{\text {st }}$ to $F_{\text {st. }}$ Genetics $183: 1,055-1,063$.

Wilford, J. N. 2008. Debate over 'little people' intensifies after recent island discovery. New York Times, March 18, 2008. https://www.nytimes.com/2008/03/18/science/18litt.html.

Wilson, P. J. 1988. The Domestication of the Human Species. New Haven, CT: Yale University Press.

Williams, F. L., R. L Belcher, and G. J. Armelagos. 2005. Forensic misclassification of ancient Nubian crania: Implications for assumptions about human variation. Curr. Anthropol. 46:340-346.

Wold, S., K. Esbensen, and P. Geladi. 1987. Principal component analysis. Chemometr. Intell. Lab. Syst. 2:37-52.

Wolpoff, M. H. 1989. Multiregional evolution: The fossil alternative to Eden. In The Human Revolution: Behavioural and Biological Perspectives in the Origins of Modern Humans, P. Mellars and C. Stringer, eds. Princeton, NJ: Princeton University Press, 62-108.

Wright, D. 2015. The genetic architecture of domestication in animals. Bioinform. Biol. Insights 9:11-20. 
Zachos, F. E. 2016. Species Concepts in Biology: Historical Development, Theoretical Foundations and Practical Relevance. Cham, Switzerland: Springer International Publishing.

Zhao, X., N. Li, W. Guo et al. 2004. Further evidence for paternal inheritance of mitochondrial DNA in the sheep (Ovis aries). Heredity 93:399-403.

Zimmerman, M. R. 1998. Alaskan and Aleutian mummies. In Mummies, Disease and Ancient Cultures, second edition, T. A. Cockburn, E. Cockburn, and T. A. Reyman, eds. Cambridge, UK: Cambridge University Press, 138-153.

Pre-print version. Visit http://digitalcommons.wayne.edu/humbiol/ after publication to acquire the final version. 
Table 1. Relationship of Hominin Discoveries to Time

Noting the relationship of discovery of fossils to their age.

\begin{tabular}{|l|l|l|l|l|}
\hline Specimen & Discoverer & Date & Sequence & Location \\
\hline 1. Neandertal & Fuhlrott & 1856 & 9 & Europe \\
\hline 2. Homo erectus & Dubois & 1891 & 8 & Java \\
\hline 3. A. africanus & Dart & 1924 & 5 & So. Africa \\
\hline 4. P. Boisei & Leakey & 1959 & 6 & East Africa \\
\hline 5. Early Homo & Leakey & 1964 & 7 & East Africa \\
\hline 6. A. afarensis & Johanson & 1978 & 4 & East Africa \\
\hline 7. A. kadabba & White & 1995 & 3 & East Africa \\
\hline 8. Orrorin tugensis & Senut & 2000 & 2 & Cen. E. Africa \\
\hline 9. Sahelanthropus & Brunet & 2002 & 1 & Cen. E. Africa \\
\hline
\end{tabular}

Pre-print version. Visit http://digitalcommons.wayne.edu/humbiol/ after publication to acquire the final version. 


\section{Figure 1.}

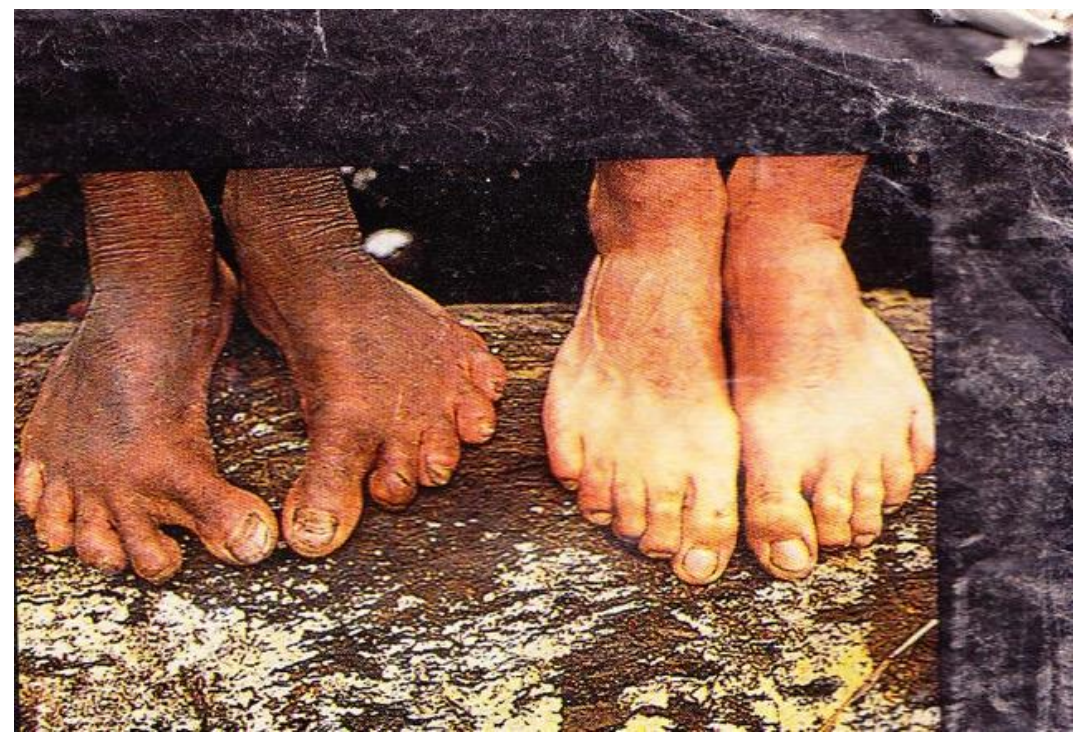

Pre-print version. Visit http://digitalcommons.wayne.edu/humbiol/ after publication to acquire the final version. 


\section{Figure 2.}
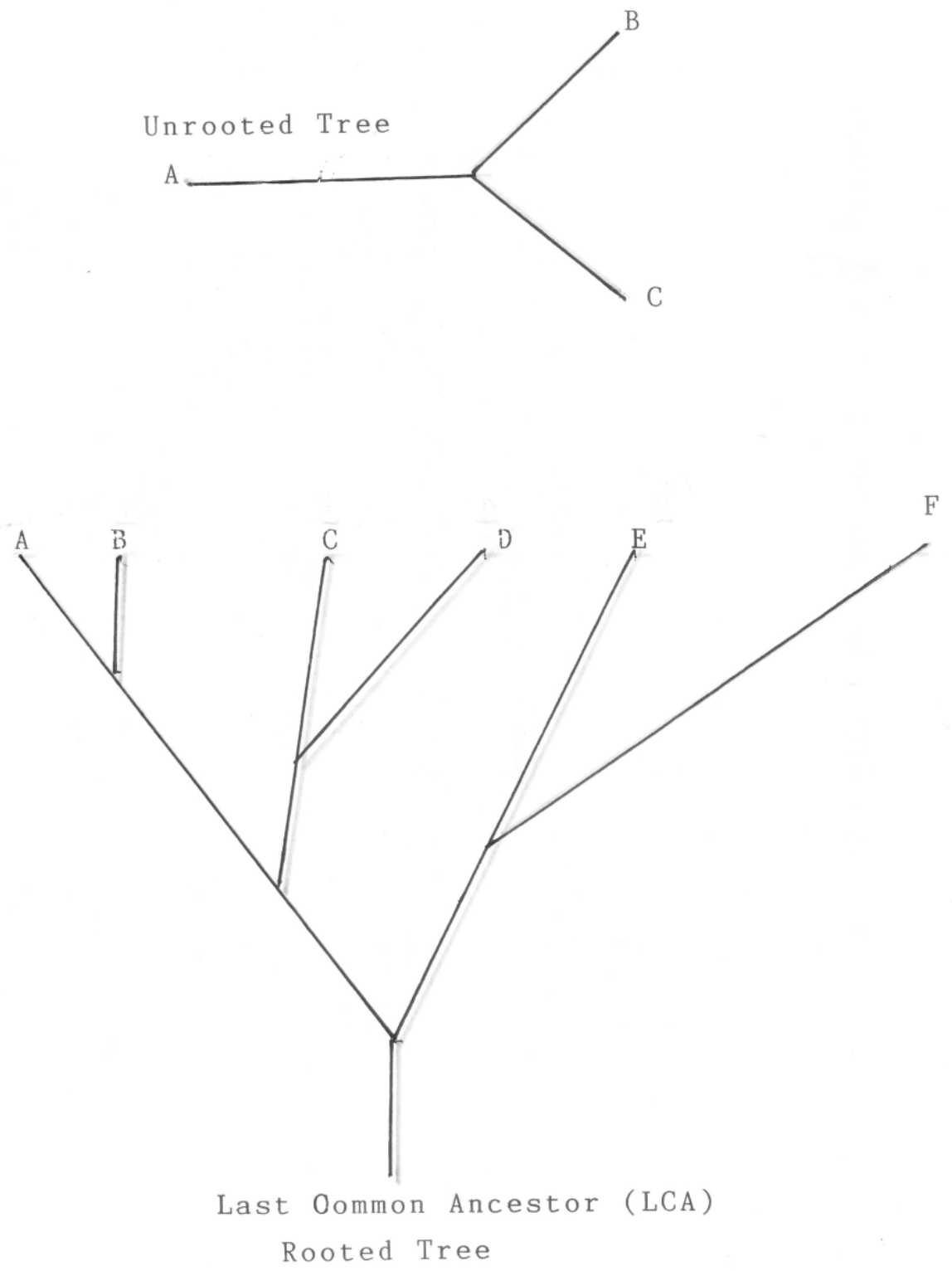

Pre-print version. Visit http://digitalcommons.wayne.edu/humbiol/ after publication to acquire the final version. 


\section{Figure 3.}

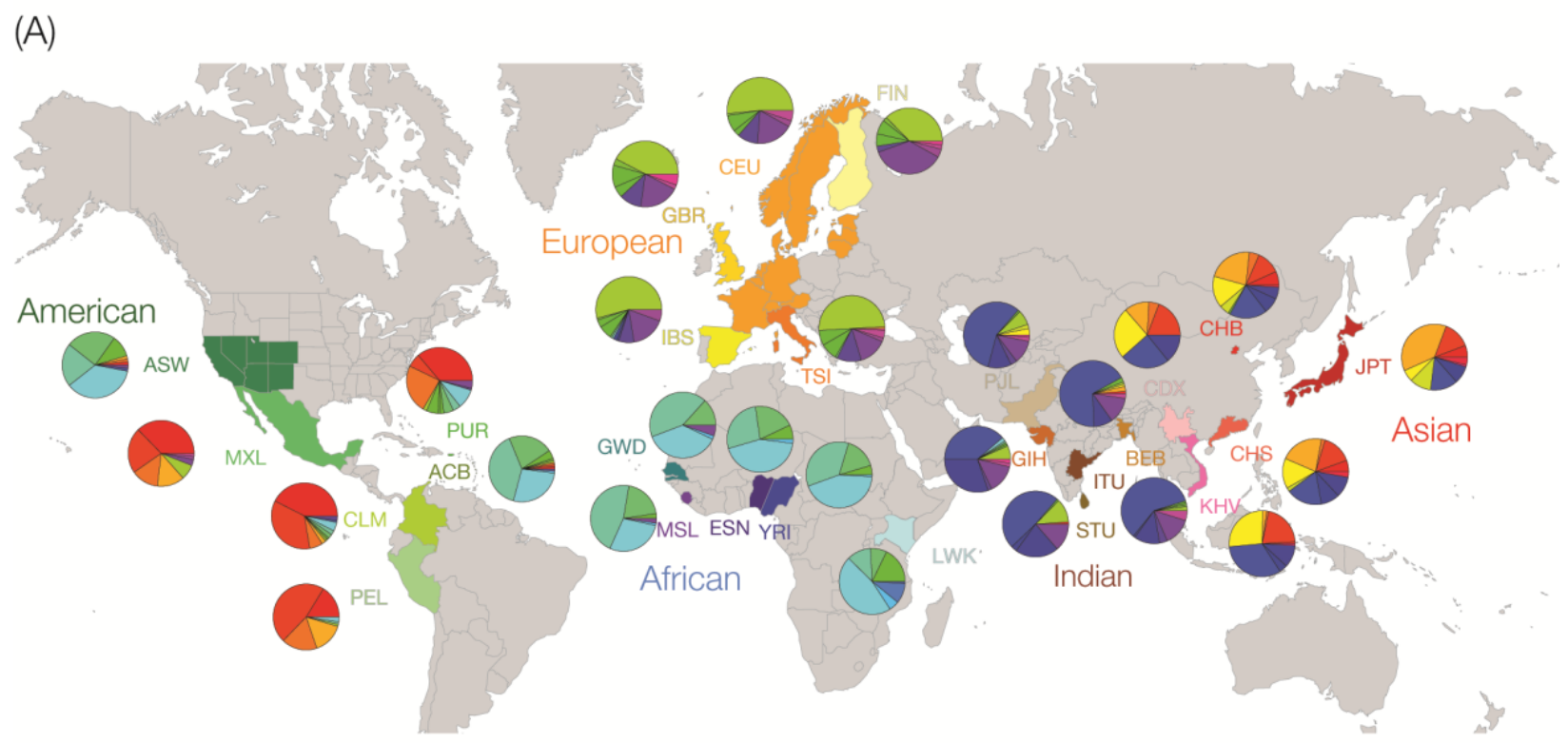

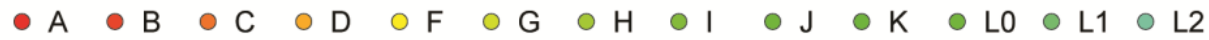

$$
\begin{aligned}
& \circ \mathrm{L} 3 \bullet \mathrm{L} 4 \bullet \mathrm{L} 5 \bullet \mathrm{M} \bullet \mathrm{N} \bullet \mathrm{R} \bullet \mathrm{T} \bullet \mathrm{U} \bullet \mathrm{V} \bullet \mathrm{W} \bullet \mathrm{X} \bullet \mathrm{Y} \bullet \mathrm{Z}
\end{aligned}
$$

(B)

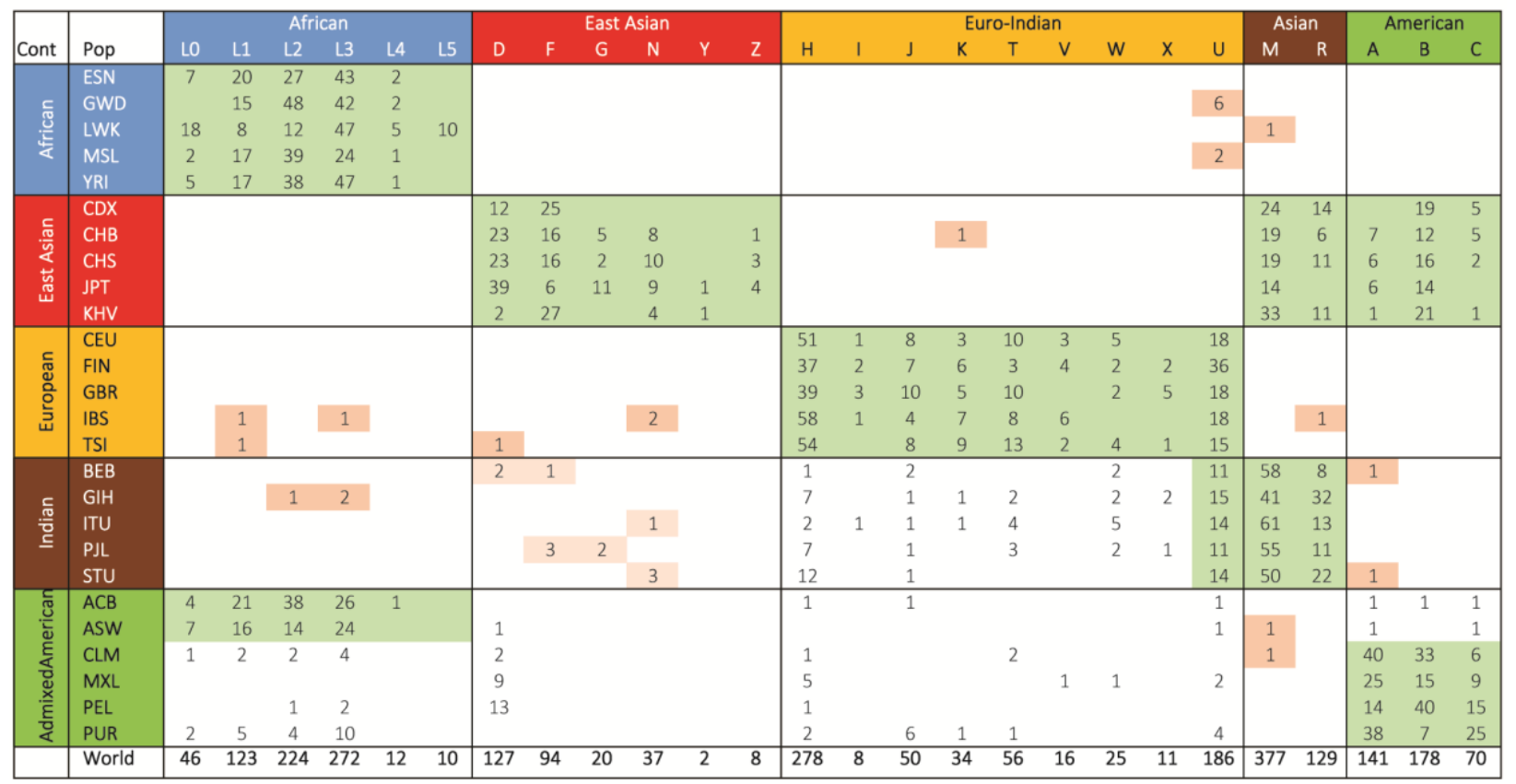




\title{
Figure 4.
}

\author{
Genes \\ 1, 2, 3, 4 \\ Ancestor A \\ 1, 2, 5, 6 \\ Ancestor B \\ 1, 2, 6, 9 \\ Descendent 1 \\ (of Ancestor B)

\section{1, 2, 4, 7 \\ Ancestor C \\ (Extinct)} \\ (n)
}




\section{Figure 5.}

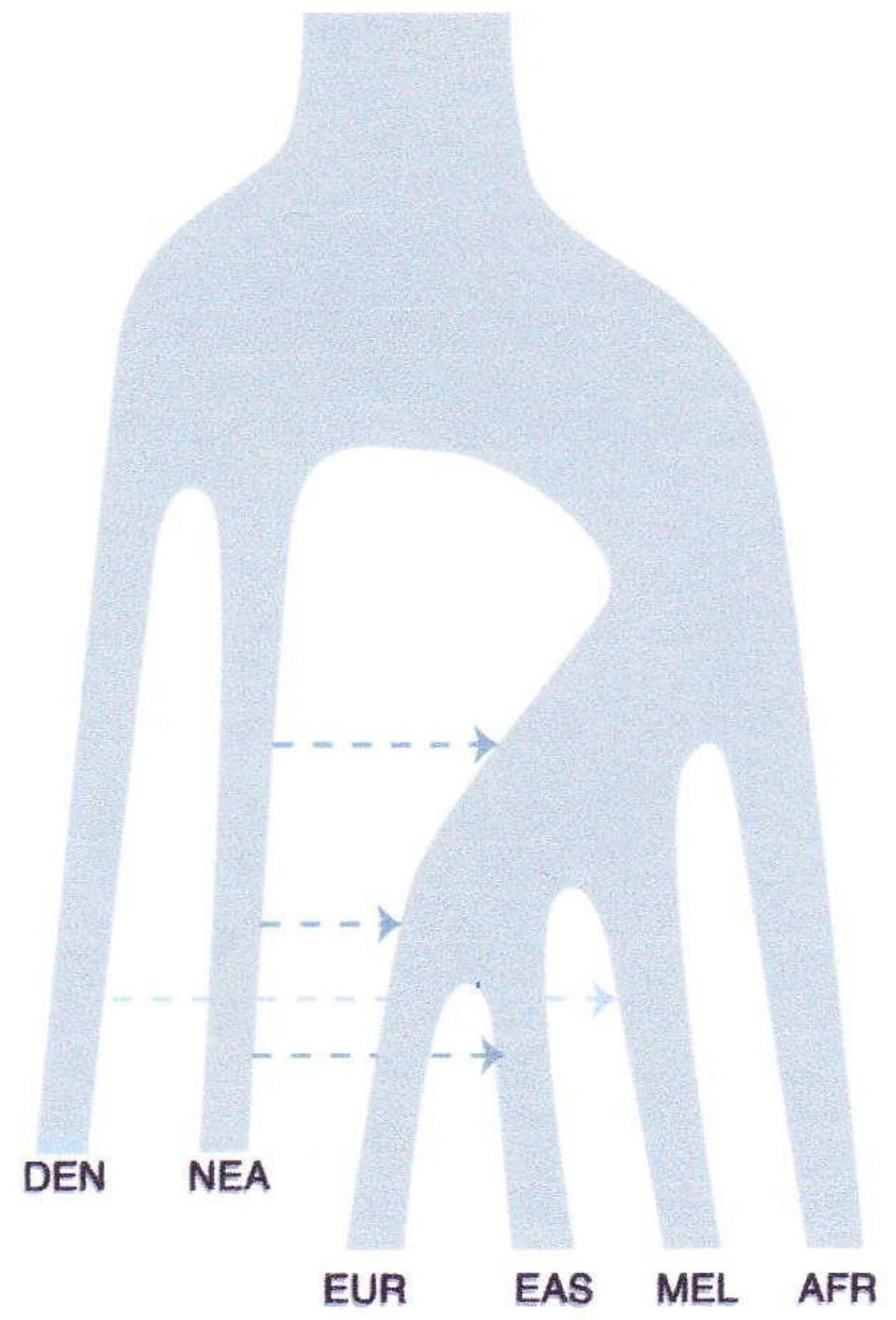

Pre-print version. Visit http://digitalcommons.wayne.edu/humbiol/ after publication to acquire the final version. 


\section{Figure 6.}

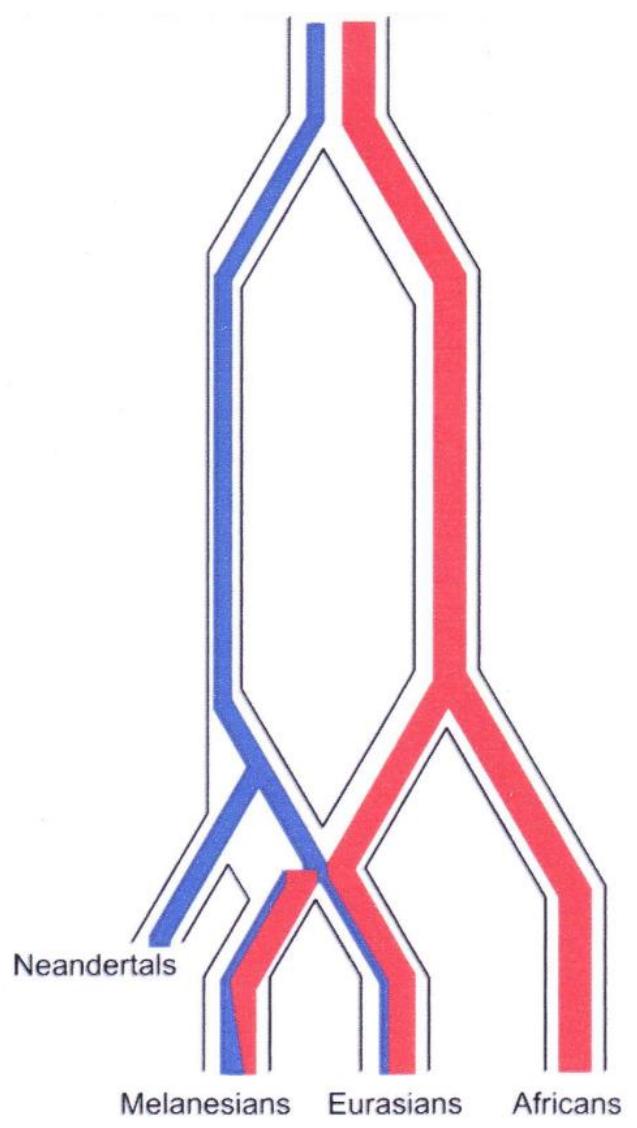

Figure S4. Schematic model for the trajectory of the alleles at STAT2. The red and blue lines represent lineages that evolved in the ancestors of AMH and Neanderthals, respectively. The Neanderthal lineage introgressed in modern humans after the out of Africa event, remaining originally at low frequency. Subsequently, the frequency of the introgressive lineage increased in Melanesians due to natural selection.

Pre-print version. Visit http://digitalcommons.wayne.edu/humbiol/ after publication to acquire the final version. 


\section{Figure 7.}

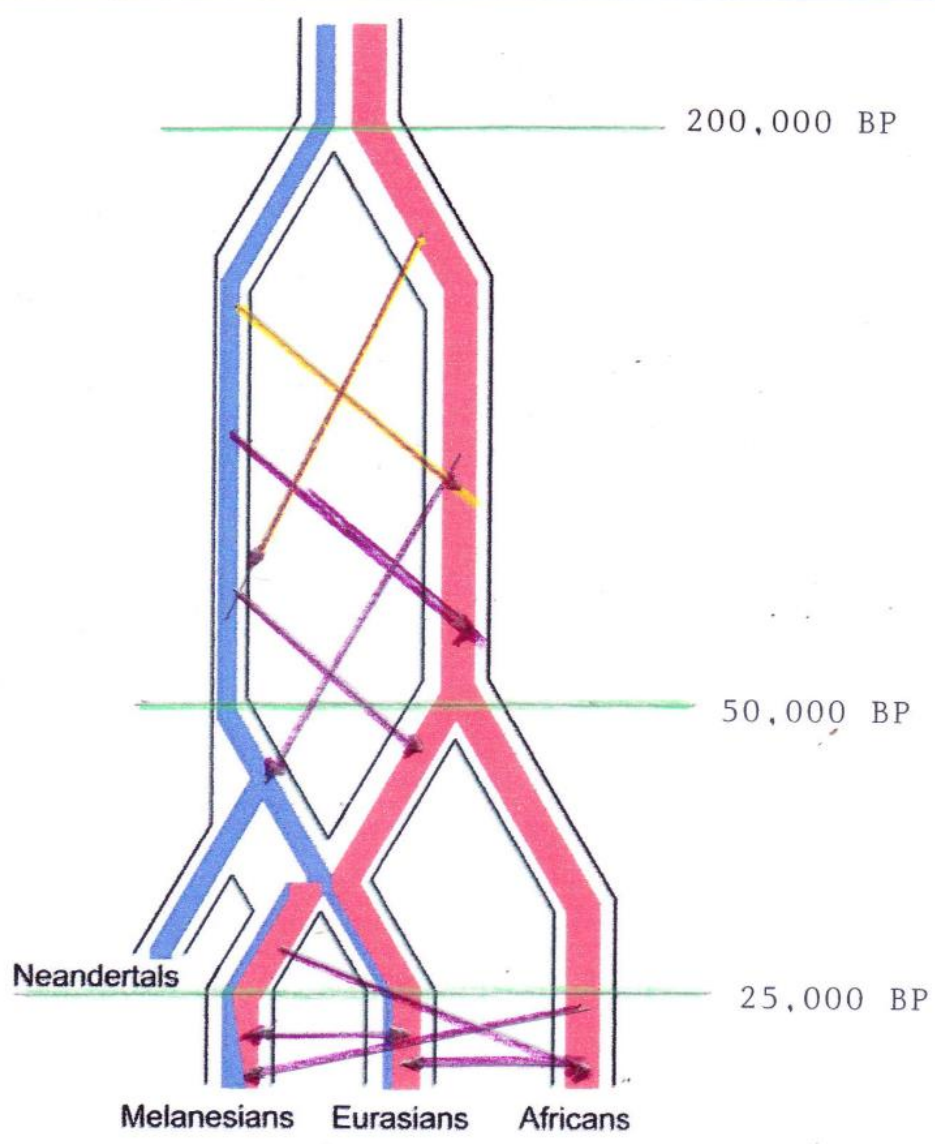

Figure S4. Schematic model for the trajectory of the alleles at STAT2. The red and blue lines represent lineages that evolved in the ancestors of AMH and Neanderthals, respectively. The Neanderthal lineage introgressed in modern humans after the out of Africa event, remaining originally at low frequency. Subsequently, the frequency of the introgressive lineage increased in Melanesians due to natural selection. 


\section{Figure Captions}

Figure 1. Feet of a Huaorni and European physical appearance due to use during development.

Figure 2. Examples of phylogenetic trees indicating the relationship between fossils shown as an unrooted tree and a rooted tree indicating the position of the Last Common Ancestor (LCA).

Figure 3. Haplotype geographic distribution by frequency. From Rishishwar et al. 2017.

Licensed under CC BY 4.0: http://creativecommons.org/licenses/by/4.0/. No modifications were made.

Figure 4. Hypothetical inheritance pattern from common ancestor.

Here we have an ancestor species A from which there are three species derived: B, C \& D.

Genes 1, 2, 3, and 4 are the ancestral genes. Genes 1 and 2 are retained as conservative and they appear in each descendent species. Where they appear in descendent species, they are inherited directly from the ancestor. Genes 5, 6, 7, 8, 9, 10, and 11 are mutations appearing in the individual histories of the separate species. In the Vernot, et al., 2016 chart reproduced here as Figure 6 the lines from Neandertals and Denisovans indicate "introcession" of mutations newly produced in these hominids into populations of early Homo sapiens sapiens at some time in the past. This difference, inherited genes from common ancestors is a distinctly different process from genes transmitted via sexual matings of hominids that are interfertile as assumed in Vernot, et al., (2016).

Figure 5. From Vernot, B., S. Tucci, J. Kelso et al. 2016. Excavating Neandertal and Denisovan DNA from the genomes of Melanesian individuals. Science 352:235-239. Reprinted with permission from AAAS.

Figure 6. Compare with evolutionary diagram of hominid evolution in Figure 7. From Mendez et al. 2012 . 
Figure 7. Modified chart from Mendez et al. (2012) indicating gene transfer.

Pre-print version. Visit http://digitalcommons.wayne.edu/humbiol/ after publication to acquire the final version. 